\title{
Battery electric vehicle adoption in Denmark and Sweden: Recent changes, related factors and policy implications
}

\author{
Haustein, Sonja; Jensen, Anders Fjendbo; Cherchi, Elisabetta
}

Published in:

Energy Policy

Link to article, DOI:

10.1016/j.enpol.2020.112096

Publication date:

2021

Document Version

Peer reviewed version

Link back to DTU Orbit

Citation (APA):

Haustein, S., Jensen, A. F., \& Cherchi, E. (2021). Battery electric vehicle adoption in Denmark and Sweden: Recent changes, related factors and policy implications. Energy Policy, 149, [112096]. https://doi.org/10.1016/j.enpol.2020.112096

\section{General rights}

Copyright and moral rights for the publications made accessible in the public portal are retained by the authors and/or other copyright owners and it is a condition of accessing publications that users recognise and abide by the legal requirements associated with these rights.

- Users may download and print one copy of any publication from the public portal for the purpose of private study or research.

- You may not further distribute the material or use it for any profit-making activity or commercial gain

- You may freely distribute the URL identifying the publication in the public portal 
Battery electric vehicle adoption in Denmark and Sweden: recent changes, related factors and policy implications

Sonja Haustein ${ }^{a^{*}}$, Anders Fjendbo Jensen ${ }^{\mathrm{a}}$, Elisabetta Cherchi ${ }^{\mathrm{b}}$

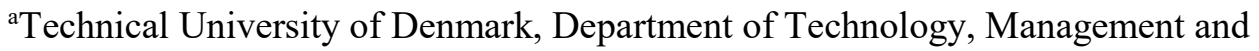
Economics, Transport Division, Bygningstorvet, 2800 Kgs. Lyngby, Denmark

${ }^{b}$ Newcastle University, School of Engineering, NE1 7RU, United Kingdom

*corresponding author

Declarations of interest:

The research was co-funded by the EU project GREAT - Green Region for Electrification and Alternative fuels for Transport (2014-EU-TM-0477-S). DTU additionally received cofunding from Region Skåne. 


\begin{abstract}
Countries worldwide are trying to increase the share of battery electric vehicles (BEVs) to reach environmental goals. As part of these efforts, the EU project GREAT installed new fast chargers in Denmark and Sweden and provided possibilities to test BEVs and inform about them. To monitor changes in attitudes and behaviours and to estimate the impact of project activities, surveys with BEV and conventional car users were conducted in 2017, 2018, and 2019. We found that attitudes and driving behaviour of BEV users and non-users remained quite stable. While car users in Denmark and Sweden showed similar profiles, one exception was a more negative evaluation of and higher uncertainty about political support for BEVs by Danes. Modelling purchase intention, we found a significant effect of the new fast chargers in Denmark but not in Sweden, while the opposite was the case for information campaigns. Lifestyle compatibility and symbolic-affective attitudes were relevant for BEV adoption in both countries. For cross-border trips, the most relevant factor was whether people had a Tesla or not, reflecting the better driving range and fast charging infrastructure. An increase of charging infrastructure, clearer policy signals and symbolic-affective marketing are discussed as ways to increase BEV adoption.
\end{abstract}

Keywords: Electric vehicles, Attitudes, Policy intervention, Awareness campaigns, Technology adoption 


\section{Battery electric vehicle adoption in Denmark and Sweden: recent changes, related factors and policy implications}

\section{Introduction}

Combined with an increase in the share of renewable energy sources in electricity production, battery electric vehicles (BEVs) can contribute to a reduction of transport-related greenhouse gas emissions (Odeh et al., 2013). In addition, BEVs help to decrease local air pollution and noise (IEA, 2016). Due to these environmental benefits, many countries have set ambitious goals for the prohibition of fossil fuel powered cars. Already in 2016, Norway announced the ban of all petrol and diesel vehicles by 2025, while many other European countries aim for a ban in 2030 (Dugdale, 2018).

A precondition for the sale of electric cars is a functioning and well-distributed charging infrastructure. For Denmark, it has been estimated that 2000 fast charging stations would be needed to reach the governments' goal of 1 million electric vehicles by 2030 (DTU and DEA, 2019). However, BEV adoption also requires that people are aware of ongoing improvements in charging infrastructure and vehicle technology. While there is evidence that BEVs are already facilitating long-distance trips among current users (Niklas et al., 2020; Tal and Turrentine, 2017), the limited driving range still hampers adoption among non-users (Liao et al., 2017).

With the installation of 70 new fast chargers in a corridor connecting Denmark, Sweden and Northern Germany, the EU project GREAT ("Green regions with alternative fuels for transport") aimed to facilitate long-distance trips by BEVs, in particular cross-border trips within Northern Europe. Additionally, the launch of 15 new fast chargers was celebrated in "Drive Clean" events. These events offered 
participants test rides with BEVs, information and family entertainment. The events aimed to raise awareness about improvements in charging infrastructure and vehicle technology and to promote the advantages and simplicity of using BEVs.

In this paper, we evaluate the effect of the new fast chargers on BEV users' conduction of cross-border trips as well as on their intention to buy a BEV again. In addition, we examine the effect of Drive Clean events on internal combustion engine vehicle (ICEV) users' intention to buy a BEV. The paper will provide insights, not only about the effect of the new infrastructure and its promotion on BEV adoption, but also about the relevance of other factors like attitudes and perceived barriers, and related changes over time in Denmark and Sweden. Based on this knowledge, policies and marketing strategies to increase BEV adoption are discussed.

The remainder of the paper is structured as follows: Section 2 provides background information on changes in BEV usage, acceptance over time and the BEV framework conditions in Denmark and Sweden. Section 3 describes the methodology followed in this research, including the data collection method and analysis as well as the survey content. Section 4 presents the results, which will be discussed in Section 5 with a particular focus on recommendations for a green transition of passenger car mobility.

\section{Background}

\subsection{Measuring changes in BEV usage and acceptance over time}

Even though the literature about BEVs is vast, the low BEV penetration level has made it difficult to measure and analyse actual BEV users' behaviour. Thus, early studies on BEV behaviour have used data based on (real or hypothetical) travel behaviour of current ICEVs users and may not be representative of which consumers 
are likely to buy BEVs and how they may adapt their travel patterns (Hardman et al., 2018; Jensen et al., 2020). The early studies that analysed BEV users' behaviour have another problem as participants tend to be "early owners of BEVs and/or people especially interested in them" (Skippon et al., 2016). Thus, they may not represent the behaviour of a more mature market.

To resolve the challenge of missing data, demonstration projects, including real vehicle trials, have often been used to measure this behaviour. To measure changes in preferences over time, some of these trials were conducted for several months and data was collected in several waves during the trial (e.g. before and after BEV experience). During such trials, mainly carried out with the previous generation of BEVs (i.e. 100-150 km driving range), participants in general obtained a more positive view on the BEV driving performance. However, their BEV purchase intention was found to have decreased (Gärling and Johansson, 1998; Franke et al., 2012; Jensen et al., 2014; Skippon et al., 2016) or remained unchanged (Schmalfuß et al., 2017) due to the disutility of short range and concerns about the ability to cover present mobility needs. A more recent field experiment showed that range anxiety can be reduced by handling a critical range situation (Rauh et al., 2020). In Norway, where the uptake of BEVs currently is the highest in the world, analyses of actual BEV user behaviour have provided some interesting results. For example, earlier studies indicated that BEV households in Norway most often also have an ICEV available (Klöckner et al., 2013; Figenbaum and Kolbenstvedt, 2016). However, the share of single vehicle BEV households is increasing, indicating a "normalisation" of BEVs as an alternative vehicle option in the population (Figenbaum and Nordbakke, 2019). 
Previous research indicates that BEVs are used for more trips than ICEVs

(Figenbaum and Kolbenstvedt, 2016; Jensen and Mabit, 2017; Labeye et al., 2016)

and mostly during weekdays and less during vacation and weekends (Figenbaum and Kolbenstvedt, 2016; Jensen and Mabit, 2017). Similarly, data from actual BEV trips show that short range BEVs are used for trips comfortably within the one way distance allowed by the driving range, whereas long range BEVs are also used for long-distance trips (Tal and Turrentine, 2017; Figenbaum and Kolbenstvedt, 2016). Even though long-distance trips constitute a very small part of annual transport needs, the eventual need for such trips might have a great influence on the car purchase decision (Nicholas and Tal, 2017), and the desire for a car that can satisfy all transport needs remains a challenge for BEV adoption (Noel et al., 2020). Studies indicate that about $70 \%-80 \%$ of all charging events occur at home (Franke and Krems, 2013; Figenbaum and Kolbenstvedt, 2016) and that workplace charging is the second most frequently used charging location (Hardman et al., 2018). Compared to ICEV users, BEV owners place less importance to public chargers, probably as they currently mostly charge at home (Chen et al., 2020). As the battery size for BEVs increases, long-distance travel will become easier and preliminary research indicates that as the driving range increases to 200 miles $(320 \mathrm{~km})$, travel behaviour tends to become similar to that using ICEVs (Nicholas et al., 2017; Figenbaum and Nordbakke, 2019). However, such travel behaviour is dependent on the supply of adequate fast charging infrastructure and currently, there is a need for more research on the implementation strategy of charging infrastructure to support the transition to long range BEVs (Hardman et al., 2018). While a recent study by Egnér and Trosvik (2018) found a general effect of the number of public 
chargers on the BEV adoption rate, the study did not distinguish between different types of chargers due to data unavailability.

Furthermore, research indicates that the general population has still little knowledge about BEVs, despite the technology has been around for decades (Axsen et al., 2017; Bailey and Axsen, 2015; Caperello et al., 2015; Gebhardt et al., 2016; Lane and Potter, 2007; Jensen et al., 2013; Krause et al., 2013). Yet, as vehicle technology and infrastructure are under permanent development, the state-of-the art is probably difficult to follow. As summarised in a review by Coffman, Bernstein and Wee (2017), the general suggestion from this literature is that "information deficiency or misperception biases consumers against EVs" (Krause et al., 2013) and that "providing consumers with the correct information or educating them on the differences between EVs and ICEVs can increase consumers' willingness to purchase EVs". Also results of a qualitative study including expert interviews across five Northern European countries stress the importance of awareness campaigns to accelerate EV adoption (Kester et al., 2018; Noel et al., 2020). Bakker and Trip (2013) suggest that cities and municipalities should provide relevant information about EVs on their website and through public events.

\subsection{BEV market penetration and policies in Denmark and Sweden}

According to IPCC (2014), transportation accounts for $14 \%$ of the world's emissions of greenhouse gases and as transport is mainly dependent on fossil fuels, several organisations and actors, including the European Union, see the use of alternative fuels in transportation as an important way to counteract global warming. The EU "Directive on the deployment of alternative fuels infrastructure" (2014/94/EU) requires member states to develop national policy frameworks for the market 
development of alternative fuels and their infrastructure and the Commission has been supporting BEVs as one of the main alternative types of propulsion technologies (Region Skåne et al., 2019).

As in Norway, the Danish government has been subsidizing BEVs by exempting this particular technology from the registration tax, which in both countries is relatively high, compared to the surrounding countries. However, as the Danish registration tax system already favoured the smallest car classes, the effect on purchase remained rather low, as the first BEV models introduced after 2010 belonged to these segments. Furthermore, the electricity providers can provide discounted electricity to private customers but the government only recently suggested to prolong discounted electricity for an additional two years until January 2022 (Skatteministeriet, 2019). This subsidy has thus been connected to a degree of uncertainty. Significant growth in 2014 and 2015 was mainly driven by the premium class Tesla Model S (Region Skåne et al., 2019), which due to the exempt of registration tax had a great advantage over the heavily taxed ICEVs in the same segment. Since 2016, the political environment has been rather unclear about BEVs. In 2015, it was decided to remove the tax subsidy gradually each year from 2016 so that by 2020 BEVs would pay full tax (Skatteministeriet, 2015). However, as the BEV market then stagnated, this law has been modified several times (e.g. Skatteministeriet, 2017). In 2019 and 2020, a BEV with a purchase cost below 400,000 DKK (54,000 Euros) is still exempt from registration tax with the expectation of an annual increase from 2021 to 2023 (Skatteministeriet, 2018). Despite the subsidies and a rather developed charging infrastructure network with approx. 350 charging points per million population, the BEV market in Denmark is still rather low with a share of $2 \%$ in the first half of 2019, largely driven by the Tesla Model 3 (Dansk Elbil Alliance, 2019). The 2019- 
elected government has a goal for Denmark to have 500,000 PEVs (BEVs and plugin hybrids) and a ban on new gasoline and diesel cars by 2030. The intent is to reach the goal by investing in charging infrastructure and prolonging the agreement on discounted electricity for private customers (Socialdemokratiet, 2019).

Sweden has a bonus-malus system in which BEVs are subsidized with 60,000 SEK and company BEVs are qualified for a $40 \%$ tax discount whereas other vehicle types are taxed according to their $\mathrm{CO}_{2}$ emissions (Region Skåne et al., 2019). Different from Denmark, plug-in hybrids have a substantial share of the market, whereas the BEV market is rather low with about 5\% of new sales in the first half of 2019 (SCB, 2019). The number of charging points per million population is slightly lower than in Denmark with about 300 chargers. The fast charge/level 2 charging point ratio, however, is higher compared to Denmark (Region Skåne et al., 2019).

\subsection{The present study}

This research is based on the results of a demonstration project carried out as part of the European project GREAT that aimed to improve the infrastructure for BEVs (installing 70 new fast chargers for BEVs in a corridor from Sweden to Northern Germany, see Figure 1) and thereby facilitating the use of BEVs for longer trips, in particular cross-border trips along that corridor (called the GREAT corridor). In addition, the project aimed to increase the acceptance of alternatively fuelled vehicles at policy and individual levels by engaging in political debates and conducting awareness campaigns. As part of this, Drive Clean events have taken place at locations where new chargers have been installed. The Drive Clean Tour started in March 2017 in the Swedish city of Värnamo and ended in October 2018 in Svendborg, Denmark. All in all, nine Swedish cities (2017-2018) followed by six 
Danish cities (2018-2019) were visited in which the launch of new chargers were celebrated, information about BEVs and other alternatively fuelled cars were distributed and test rides offered (Region Skåne, 2020). On average, 30 test rides were conducted per event and the events were covered in local media. The Danish cities included three of the largest cities in Denmark (Copenhagen, Aarhus, Aalborg), while apart from Malmö, the Swedish events mainly took place in smaller cities. As part of the demonstration project, online surveys among current users of BEVs and ICEVs were conducted in Denmark and Sweden in 2016-2017, 2018, and 2019. The surveys collected information about car availability and usage, attitudes, perceived barriers and purchase intentions towards BEVs and how these factors changed from the end of 2016 to the beginning of 2019.

To assess the effect of GREAT activities, we estimated the effect of Drive Clean events on ICEV users' purchase intention and the effect of GREAT fast chargers on BEV users' purchase intention and on the conduction of cross-border trips by BEVs. While cross-border trips can be regarded as proxies for long-distance trips, they may also include shorter trips for people living close to the border or bring additional challenges in form of compatibility problems.

Apart from the effect of the new infrastructure and campaigns, we also examined which other factors are relevant for BEV adoption among ICEV and BEV users in Denmark and Sweden to provide knowledge for future efforts to increase BEV adoption. 


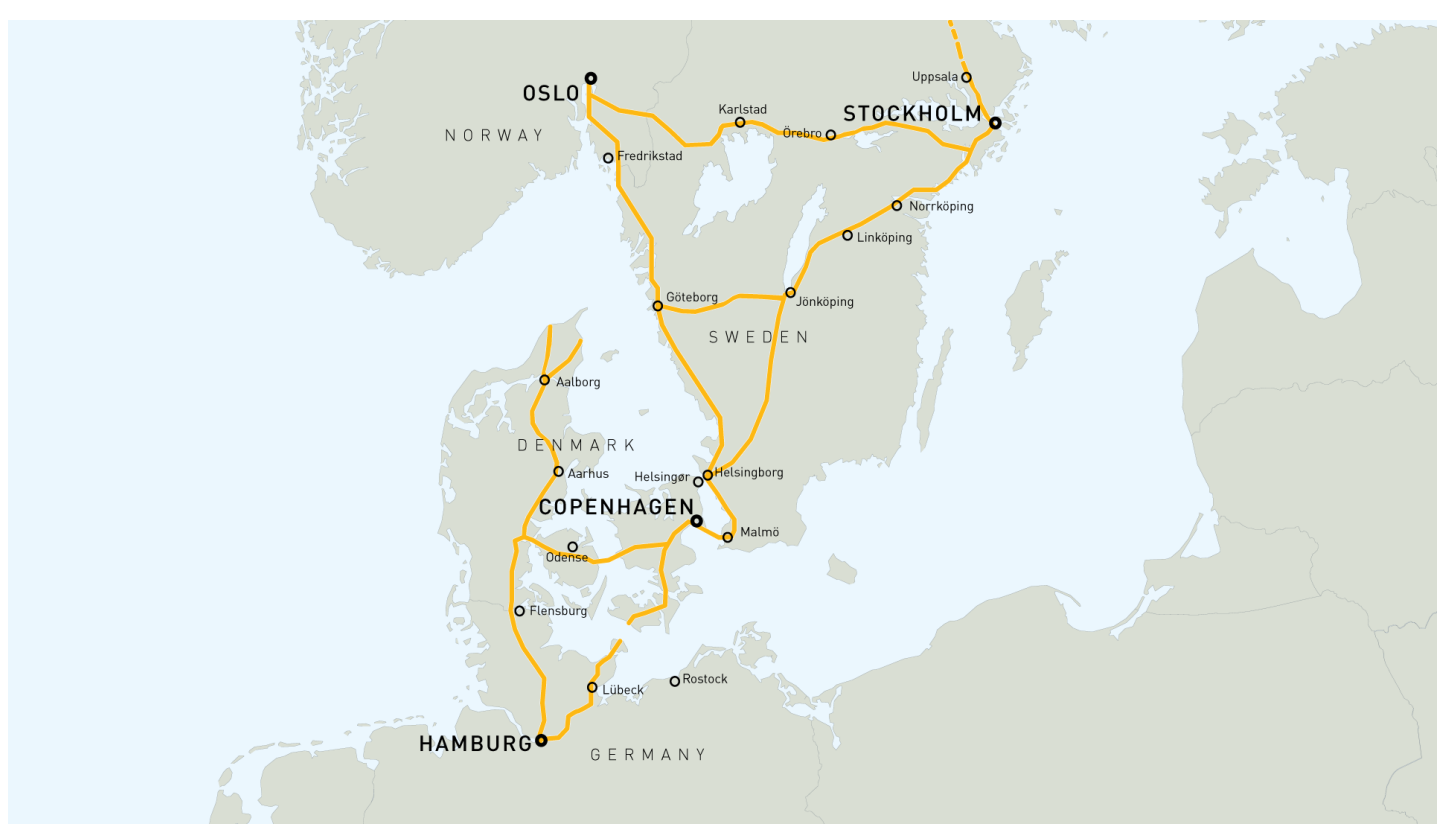

Figure 1: The GREAT corridor

\section{Methodology}

\subsection{Data collection: Procedure and participants}

The data for this study was collected yearly via online surveys in Denmark and Sweden in three waves, each one lasting about 2 months: Wave 1: End of November 2016-February 2017 (with a break during Christmas holidays); Wave 2: JanuaryFebruary 2018; Wave 3: January-February 2019.

The target population was two groups of drivers:

1) drivers with at least one ICEV (and no other car types) in the household ("ICEV users");

2) drivers with at least one BEV in the household and possibly other car types ("BEV users").

Whether or not people participated in the survey in the first waves was not a criterion for being included in the survey in the following waves. BEV users were surveyed in all three waves, while ICEV users were surveyed only in the first and last wave. 
Yearly intervals were found relevant for changes in BEV usage in relation to the awareness of new fast chargers, but to a lesser extent in relation to more general changes in attitudes and intentions, which were expected to be more stable.

BEV users were mainly recruited through the energy provider E.ON, who sent out emails with a survey link to their E-mobility customers. In Sweden, additional ways to contact BEV users (e.g. Facebook groups, mailing lists) were used, as the number of E.ON customers was too small at the beginning of the evaluation study. This also explains the much higher number of participants in wave 3, where E.ON had significantly increased its market penetration. Thus, wave 1 probably includes more engaged and enthusiastic BEV users (those being active in user forums), while the other waves are expected to be more representative for BEV users - and also more comparable to the Danish sample.

ICEV users in Denmark (wave 1 \& 3) and in Sweden (wave 3) were recruited among members of online panels by the market research institutes Epinion (Denmark) and Norstat (Sweden), respectively. The Danish panel ("Danmarkspanelet") consists of about 250,000 members covering all regions of Denmark. Panel membership is rewarded with regular participation in lotteries (see Epinionglobal.com for details). The Swedish panel consists of 144,000 panelists. Criteria for participation in the survey were possession of a driver's license and having one or more ICEVs in the household but no alternatively fuelled car.

In Denmark, $50 \%$ of the ICEV sample was recruited in the Capital Region of Denmark, and $50 \%$ in the rest of the country. In Sweden, the following quotas were used: 20\% Stockholm Region; 20\% Region Västra Götaland/Göteborg; 20\% Skåne/Malmö 20\%; 40\% rest of the country. We oversampled urban areas to better match the sample of ICEV users with BEV users. The percentages roughly followed 
BEV sales statistics, which we received from car companies involved in the project. However, in the first wave of data collection in Sweden, a convenience sample was used for practical reasons. Thus, this sample is not completely comparable with the other samples. For the purpose of the effect assessment, this difference is not considered relevant as the analysis includes (and thus controls for) potential factors related to the difference in sampling. The sampling difference of wave 1 related to both Swedish BEV and ICEV users will be taken into account when discussing the descriptive results. Table 1 provides an overview of the samples in Denmark and Sweden, separated for all survey waves. 
Table 1: Sampling across all three survey waves

\begin{tabular}{lcccc}
\hline & & ICEV & BEV \\
\hline Denmark & Wave & 1 & 829 & 508 \\
& 2 & - & 677 \\
& & 3 & 551 & 477 \\
\cline { 2 - 5 } & Total & 1380 & 1662 \\
\hline Sweden & Wave & 1 & 964 & 165 \\
& & 2 & - & 217 \\
& & 3 & 1569 & 818 \\
\hline Total & Wave & 1 & 1793 & 1200 \\
& & 2 & - & 673 \\
& & & 1156 & 894 \\
& & & 2949 & 1295 \\
& Total & & & 2862 \\
\hline
\end{tabular}

Table 2 shows the differences in the socio-demographic profiles of BEV and ICEV users in Denmark and Sweden for the entire survey (all waves together). In both countries, BEV and ICEV users differ significantly $(\mathrm{p}<.001)$ in all the demographic variables considered: Typical BEV users are middle-aged men with high income and education, living in a detached house and in households with more than one car (especially in Sweden). While Swedes more often than Danes have more than one car in the household, both countries have similar percentages of people driving (almost) daily, and in both countries, this percentage is higher for BEV users (around $80 \%)$ than ICEV users (58\%). The profiles of BEV users resemble the results found in earlier studies (e.g. Hjorthol, 2013; Nayum et al., 2016; Peters and Dütschke, 2014). A more detailed comparison of both user groups based on data of the first survey wave is included in Haustein and Jensen (2018). 
Table 2: Profiles of BEV and ICEV users in Denmark and Sweden

\begin{tabular}{|c|c|c|c|c|c|c|c|}
\hline & & DK & & & SE & & \\
\hline & & ICEV & $\mathrm{BEV}$ & total & ICEV & BEV & total \\
\hline \multirow[t]{4}{*}{ Gender } & Men & 723 & 1484 & 2207 & 642 & 1098 & 1740 \\
\hline & & $52.4 \%$ & $89.8 \%$ & $72.8 \%$ & $41.0 \%$ & $93.1 \%$ & $63.3 \%$ \\
\hline & Women & 657 & 169 & 826 & 925 & 82 & 1007 \\
\hline & & $47.6 \%$ & $10.2 \%$ & $27.2 \%$ & $59.0 \%$ & $6.9 \%$ & $36.7 \%$ \\
\hline \multirow[t]{6}{*}{ Age } & $18-35 \mathrm{y}$ & 365 & 150 & 515 & 280 & 106 & 386 \\
\hline & & $26.6 \%$ & $9.1 \%$ & $17.0 \%$ & $17.9 \%$ & $9.0 \%$ & $14.1 \%$ \\
\hline & $36-59 \mathrm{y}$. & 600 & 1123 & 1723 & 900 & 837 & 1737 \\
\hline & & $43.8 \%$ & $68.0 \%$ & $57.0 \%$ & $57.5 \%$ & $70.8 \%$ & $63.2 \%$ \\
\hline & $60+y$ & 406 & 379 & 785 & 384 & 240 & 624 \\
\hline & & $29.6 \%$ & $22.9 \%$ & $26.0 \%$ & $24.6 \%$ & $20.3 \%$ & $22.7 \%$ \\
\hline \multirow[t]{4}{*}{ Income } & $<50.000 \mathrm{kr}$ & 910 & 778 & 1688 & 1242 & 829 & 2071 \\
\hline & & $80.9 \%$ & $52.5 \%$ & $64.7 \%$ & $88.5 \%$ & $73.2 \%$ & $81.6 \%$ \\
\hline & $50.000 \mathrm{kr}$ and more & 215 & 704 & 919 & 162 & 304 & 466 \\
\hline & & $19.1 \%$ & $47.5 \%$ & $35.3 \%$ & $11.5 \%$ & $26.8 \%$ & $18.4 \%$ \\
\hline \multirow[t]{3}{*}{ Education } & Higher & 630 & 1256 & 1886 & 772 & 671 & 1443 \\
\hline & education & & & & & & \\
\hline & & $46.3 \%$ & $77.3 \%$ & $63.2 \%$ & $51.0 \%$ & $57.7 \%$ & $53.9 \%$ \\
\hline \multirow{2}{*}{$\begin{array}{l}\text { Cars in } \\
\text { household }\end{array}$} & More than 1 car & 433 & 981 & 1414 & 766 & 846 & 1612 \\
\hline & & $31.4 \%$ & $59.0 \%$ & $46.5 \%$ & $48.8 \%$ & $70.5 \%$ & $58.2 \%$ \\
\hline Car use $(5$ & & 796 & 1347 & 2143 & 903 & 942 & 1845 \\
\hline $\begin{array}{l}\text { times a week } \\
\text { or more) }\end{array}$ & & $57.7 \%$ & $81.1 \%$ & $70.5 \%$ & $57.6 \%$ & $78.5 \%$ & $66.6 \%$ \\
\hline \multirow[t]{2}{*}{ Housing } & Detached house & 287 & 811 & 1098 & 276 & 764 & 1040 \\
\hline & & $52.3 \%$ & $70.8 \%$ & $64.8 \%$ & $45.8 \%$ & $74.9 \%$ & $64.1 \%$ \\
\hline
\end{tabular}

For Denmark (where the sampling method was the same across the three waves), we examined if the demographic compositions of BEV users changed from wave 1 to wave 3, getting more similar to the demographic composition of ICEV users. This would indicate higher market penetration among the "normal" population. Even though we found that the percentage of women increased from $9 \%$ to $12 \%$ and the percentage of people with higher income decrease from $49 \%$ to $44 \%$, none of these 
differences were significant $(p>.10)$. By contrast, we found that the percentage of people aged 60 and above increased significantly from $21 \%$ to $27 \%(\mathrm{p}<.05)$.

\subsection{Measures}

The data was collected by online questionnaires designed and operated with Qualtrics survey software. First, a master questionnaire in English was developed, which was then translated to Danish and Swedish. The different versions were crosschecked by Danish and Swedish native speakers, who were familiar with all three languages and with the topic of research. Participants could choose to complete the survey either in the national language or in English. The questionnaire included the following aspects:

Car availability and use: The questionnaire asked for the number and type of cars available in the household and details on car usage $(\mathrm{km}$ driven per car type each week, use of car type for cross-border trips within the past 5 years). For electric cars, the car make was additionally requested. Non-BEV users were provided with the information that 'battery electric cars do not use fuel but electrical energy stored in batteries that need to be charged' to ensure that all participants had a basic knowledge of BEVs.

Attitudinal factors: The questionnaire included several variables to measure attitudes and norms related to BEVs. Attitudinal variables were based on an extended version of the Theory of Planned Behaviour (Ajzen, 1991) and assessed on a 5-point Likert scale ranging from "totally disagree" (1) to "totally agree" (5). The theoretical background of the items used in the first wave is presented in more detail in Haustein and Jensen (2018). In waves 2 and 3, we added some items to better capture the perceived compatibility of EVs to the personal lifestyle (items adapted from Peters and Dütschke, 2014) as well as perceived uncertainty about political support 
(developed for this survey). The attitudinal items used in wave 1 remained

unchanged (see Table 3 for a complete item list). People with no personal experience with electric cars were asked to indicate their expectations when answering to the statements.

BEV attributes: Eight BEV attributes (e.g. prize, driving range, see Figures 4 and 5) were additionally assessed with regard to satisfaction ("very dissatisfying" (1) "very satisfying" (5) and their importance in a purchase decision ("not important at all" (1) - "very important" (5)). In case of BEV users, the assessment was related to the latest BEV purchase, while for ICEV users it was related to the potential purchase. For the assessment of BEV attributes, “don't know” was provided as an additional answer option as a pilot test before the first wave revealed that many people felt too unexperienced to answer these questions.

Awareness of new chargers: The questionnaires addressing BEV users in waves 2 and 3 included a list of all chargers built as part of the GREAT project until the time of data collection. BEV users were asked to indicate if they had seen and/or used each of the chargers listed.

Demographic variables included age, gender, household size, number of children under 10 years of age, highest completed education, household income, kind of housing, and employment status.

It took about 10-20 min. to complete the online survey, mostly depending on the number of available car types in the household.

\subsection{Analysis}

ANOVA's or $\mathrm{Chi}^{2}$ tests were conducted to analyse differences between countries and waves, depending on the scale of measurement. Differences between the usage of 
different car types and between the assessment of importance and satisfaction of BEV attributes were tested with paired t-tests.

Principal component analyses (PCA) with Varimax rotation were used to reduce the attitudinal variables to their underlying dimensions. Analyses were first conducted separately for countries and BEV versus ICEV users but as the resulting factor structures were very similar, data from the complete survey in wave 2 and 3 were finally used (wave 1 was not included as some items were first added in wave 2). For the effect assessment, separate multiple regressions were calculated to model the impact of activities of the GREAT project (new fast chargers and Drive Clean events). For BEV users, the effects of newly built fast chargers on cross-border trips and purchase intention were assessed using the number of fast chargers built in the GREAT project that people had seen and/or used. For ICEV users, the effect of Drive Clean events was assessed with a variable that indicated whether users lived in a municipality where an event had taken place before survey participation. In all analyses, several other variables (demographics, car use and ownership) were included as control variables.

The effect of new fast chargers on the conduction of cross-border trips (had a cross border trip or not) was assessed by multiple logistic regressions, the effects of new chargers (BEV users) and Drive Clean events (ICEV users) on purchase intention were assessed with multiple linear regressions. All models were calculated separately for Denmark and Sweden.

We calculated all regressions excluding and including attitudinal factors, referred to as model 1 and model 2, respectively. The attitudinal factors were not included in model 1, as we expected them to be influenced by GREAT activities (new chargers, awareness campaigns) as well. Thus, when including them, the effect of GREAT 
activities is reduced by the effect that is already covered by (potentially changed) attitudes. In model 2, the attitudinal factor were included to assess their importance for purchase intention and cross-border trips, while controlling for demographic and GREAT activities.

\section{Results}

The description of the results is divided into three sections. Section 4.1 focusses on attitudinal factors related to BEVs, related changes over time and country differences. Section 4.2 describes the extent to which BEVs were used for trips to other countries. We examined whether the usage changed over time and differed between countries. Finally, Section 4.3 looks into the factors affecting BEV purchase intention and the conduction of cross-border trips, particularly the role played by the installation of the new fast chargers and Drive Clean events - the key activities within the GREAT project.

\subsection{Attitudes and norms with regard to BEVs}

Both BEV and ICEV users were asked about their attitudes and norms with regard to BEVs. To reduce the attitudes, perceived barriers and norms to their underlying dimensions, a principal component analysis (PCA) was conducted based on the 23 attitudinal items included in the questionnaires in waves 2 and 3. Based on the Eigenvalue criterion, five factors were extracted, which explain $66 \%$ of the total variance. The loadings of the single variables on the five factors are shown in Table 3. The only unexpected result we found is that the variables that are supposed to measure "Lifestyle comparability" do not form a separate factor but have the highest 
loadings on the factor related to symbolic-affective attitudes. Even though these constructs are correlated, we will treat the three items related to Lifestyle comparability as a separate factor as they clearly differ by content.

Thus, we differentiate between the following six attitudinal dimensions: Status and excitement (factor 1) summarises symbolic and affective motives in relation to BEV ownership and use, for example feelings of pride in relating to BEV ownership (vs. embarrassment), fascination by BEV technology and driving performance, and excitement in relation to driving a BEV. Perceived functional barriers (factor 2) refers to functional barriers in relation to $\mathrm{BEV}$ use, such as range anxiety, inconvenience of charging, and the need for planning. Social norm (factor 3) includes descriptive social norm that is the adoption of BEVs by individuals important to the respondent, as well as the anticipated support of own BEV adoption by individuals important to the respondent (injunctive norm). Environmental norm (factor 4) measures the moral obligation to consider environmental consequences when choosing a car. Lifestyle comparability (part of factor 1) refers to how driving an electric car is suited to carry out daily tasks and generally how it is perceived to fit to the individual's lifestyle. Uncertain political support (factor 5) refers to the perception of uncertainty about political support for electric cars in Denmark or Sweden, respectively. 
Table 3: Results of a principal component analysis (wave 2 and 3, $N=3305$ )

Factor 1 Factor 2 Factor 3 Factor 4 Factor 5

It is fun to drive an electric car.

The fast acceleration of an electric car is an exciting experience.

I'm fascinated by the technology of electric cars.

I (would) feel embarrassed when driving an electric car. ${ }^{\mathrm{a}}$

I (would) feel proud of having an electric car. ${ }^{a}$

Driving an electric car expresses (my) openness for new technologies. ${ }^{\mathrm{a}}$

Driving an electric car is easily compatible with my habits. ${ }^{b}$

An electric car is well suited to carry out my daily tasks. ${ }^{\mathrm{b}}$

Electric cars are not suitable for my lifestyle.

The need for charging makes electric cars very unpractical for use in everyday life.

Ensuring that an electric car is always charged $-0.35$

0.76

$$
-0.16
$$

0.20

0.24

$\mathbf{0 . 7 3} 0.03$

0.16

$0.12-0.04$

$\begin{array}{lllll}\mathbf{0 . 6 7} & -0.38 & 0.20 & 0.20 & 0.06\end{array}$

$\begin{array}{lllll}\mathbf{0 . 6 3} & -0.37 & 0.08 & 0.18 & 0.06\end{array}$
makes it inconvenient to use.

Using an electric car requires a careful

$\begin{array}{lllll}-0.03 & \mathbf{0 . 7 6} & -0.07 & 0.02 & 0.12\end{array}$

planning of activities.

When driving an electric car, I'm always

$\mathbf{0 . 7 7}$

$-0.11-0.09$

$-0.04$

(would always be) worried about running out

of charge. ${ }^{\mathrm{a}}$

Using an electric car for longer distances is

0.73

$-0.15$

0.02

0.04

difficult due to a lack of charging stations

along the motorway.

People who are important to me are

0.24

$-0.19$

0.77

0.18

$-0.04$

considering to buy an electric car.

People who are important to me own an

0.05

$-0.08$

$\mathbf{0 . 7 7}-0.03$

$-0.02$

electric car.

People who are important to me think that my

0.23

$-0.17$

0.74

0.26 
People who are important to me think that

electric cars should play an important role in our transport system.

\begin{tabular}{|c|c|c|c|c|c|}
\hline $\begin{array}{l}\text { If I buy a car, I feel morally obliged to choose a } \\
\text { car that minimises carbon emissions and air } \\
\text { pollution. }\end{array}$ & 0.22 & -0.06 & 0.25 & 0.86 & 0.03 \\
\hline $\begin{array}{l}\text { I feel obliged to take environmental } \\
\text { consequences of vehicle use into account when } \\
\text { choosing a car. }\end{array}$ & 0.23 & -0.08 & 0.25 & 0.85 & 0.03 \\
\hline $\begin{array}{l}\text { Future political support for electric cars is very } \\
\text { uncertain in Denmark/Sweden. }^{\text {b }}\end{array}$ & 0.14 & 0.00 & 0.06 & 0.02 & 0.86 \\
\hline $\begin{array}{l}\text { The development of public incentives for } \\
\text { electric cars is very unpredictable in }\end{array}$ & 0.15 & -0.01 & 0.04 & 0.01 & 0.85 \\
\hline Denmark/Sweden. ${ }^{\mathrm{b}}$ & & & & & \\
\hline $\begin{array}{l}\text { The resale value of electric cars is very } \\
\text { unpredictable. }{ }^{b}\end{array}$ & -0.06 & 0.38 & -0.16 & 0.05 & 0.50 \\
\hline
\end{tabular}

Notes. ${ }^{a}$ Different formulation for BEV and ICEV users. ${ }^{\mathrm{b}}$ Items not included in survey wave 1.

Table 4 shows the level of agreement to the different single items related to these attitudinal dimensions, separated by country and car user group. While BEV users have generally much more positive attitudes towards BEVs as compared with ICEV users, we also find several significant differences between countries. However, most of them are not very strong as indicated by the low $\mathrm{Eta}^{2}$ values. Yet, we found a remarkable difference with regard to political support, which a large majority of BEV users in Denmark feel uncertain about. Danes also perceive higher functional barriers towards BEV use than Swedes. 
Table 4: Percentage of agreement ${ }^{a}$ to statements related to different attitudinal

dimensions by BEV and ICEV users in Denmark and Sweden (wave 3)

\begin{tabular}{|c|c|c|c|c|c|c|c|c|}
\hline & \multicolumn{4}{|l|}{$\mathrm{BEV}$} & \multicolumn{4}{|l|}{ ICEV } \\
\hline & DK & SE & & $\mathrm{Eta}^{2}$ & DK & $\mathrm{SE}$ & & $\mathrm{Eta}^{2}$ \\
\hline \multicolumn{9}{|l|}{ Status and excitement } \\
\hline It is fun to drive an electric car. & $94.1 \%$ & $95.9 \%$ & $* * *$ & 0.02 & $36.8 \%$ & $40.3 \%$ & & 0.00 \\
\hline $\begin{array}{l}\text { The fast acceleration of an electric car is an } \\
\text { exciting experience. }\end{array}$ & $88.2 \%$ & $85.6 \%$ & $* *$ & 0.00 & $44.7 \%$ & $41.7 \%$ & & 0.00 \\
\hline I'm fascinated by the technology of electric cars. & $84.6 \%$ & $85.1 \%$ & $* * *$ & 0.00 & $47.4 \%$ & $51.0 \%$ & & 0.00 \\
\hline $\begin{array}{l}\text { I (would) feel embarrassed when driving an } \\
\text { electric car. }{ }^{\text {b,c }}\end{array}$ & $0.2 \%$ & $0.1 \%$ & & 0.01 & $2.3 \%$ & $4.0 \%$ & $*$ & 0.00 \\
\hline I (would) feel proud of having an electric car. ${ }^{\text {b }}$ & $88.8 \%$ & $91.7 \%$ & & 0.01 & $47.8 \%$ & $52.6 \%$ & & 0.00 \\
\hline $\begin{array}{l}\text { Driving an electric car expresses }(m y) \text { openness } \\
\text { for new technologies. }{ }^{b}\end{array}$ & $79.7 \%$ & $87.5 \%$ & $* * *$ & 0.02 & $60.1 \%$ & $64.8 \%$ & & 0.00 \\
\hline \multicolumn{9}{|l|}{ Perceived functional barriers } \\
\hline $\begin{array}{l}\text { The need for charging makes electric cars very } \\
\text { unpractical for use in everyday life. }\end{array}$ & $9.7 \%$ & $4.1 \%$ & $* * *$ & 0.03 & $46.6 \%$ & $39.4 \%$ & $* * *$ & 0.01 \\
\hline $\begin{array}{l}\text { Ensuring that an electric car is always charged } \\
\text { makes it inconvenient to use. }\end{array}$ & $16.9 \%$ & $8.9 \%$ & $* * *$ & 0.03 & $48.8 \%$ & $45.6 \%$ & $*$ & 0.00 \\
\hline $\begin{array}{l}\text { Using an electric car requires a careful planning } \\
\text { of activities. }\end{array}$ & $55.4 \%$ & $40.4 \%$ & $* * *$ & 0.03 & $59.7 \%$ & $60.1 \%$ & & 0.00 \\
\hline $\begin{array}{l}\text { When driving an electric car, I'm always (would } \\
\text { always be) worried about running out of charge. }\end{array}$ & $13.5 \%$ & $12.8 \%$ & $* *$ & 0.00 & $53.1 \%$ & $55.2 \%$ & & 0.00 \\
\hline $\begin{array}{l}\text { Using an electric car for longer distances is } \\
\text { difficult due to a lack of charging stations along } \\
\text { the motorway. }\end{array}$ & $42.4 \%$ & $42.8 \%$ & & 0.00 & $70.4 \%$ & $69.8 \%$ & & 0.00 \\
\hline \multicolumn{9}{|l|}{ Social norm } \\
\hline $\begin{array}{l}\text { People who are important to me are considering } \\
\text { to buy an electric car. }\end{array}$ & $44.9 \%$ & $52.2 \%$ & $*$ & 0.01 & $11.7 \%$ & $16.2 \%$ & & 0.00 \\
\hline $\begin{array}{l}\text { People who are important to me own an electric } \\
\text { car. }\end{array}$ & $13.5 \%$ & $17.8 \%$ & & 0.00 & $7.4 \%$ & $8.5 \%$ & & 0.00 \\
\hline $\begin{array}{l}\text { People who are important to me think that my } \\
\text { next car should be an electric car. }\end{array}$ & $34.5 \%$ & $37.6 \%$ & & 0.00 & $10.2 \%$ & $14.0 \%$ & & 0.00 \\
\hline $\begin{array}{l}\text { People who are important to me think that electric } \\
\text { cars should play an important role in our transport } \\
\text { system. }\end{array}$ & $56.8 \%$ & $56.5 \%$ & & 0.00 & $24.0 \%$ & $25.5 \%$ & & 0.00 \\
\hline VII & & & & & & & & \\
\hline
\end{tabular}


If I buy a car, I feel morally obliged to choose a

car that minimises carbon emissions and air

$75.9 \% \quad 76.1 \%$

$0.00 \quad 48.2 \% \quad 52.9 \%$

0.00

pollution.

I feel obliged to take environmental consequences

of vehicle use into account when choosing a car.

$\begin{array}{lllllll}78.7 \% & 75.0 \% & * & 0.00 & 50.8 \% & 50.7 \% & 0.00\end{array}$

Lifestyle comparability

Electric cars are not suitable for my lifestyle. ${ }^{c}$

$\begin{array}{lllllll}2.3 \% & 9.3 \% & 0.01 & 16.9 \% & 14.9 \% & * * & 0.01\end{array}$

Driving an electric car is easily compatible with my habits.

$\begin{array}{llllll}90.7 \% & 89.6 \% & 0.00 & 36.4 \% & 43.5 \% & 0.00\end{array}$

An electric car is well suited to carry out my daily tasks.

$\begin{array}{lllllllll}96.2 \% & 96.2 \% & * * * & 0.01 & 57.7 \% & 66.4 \% & * * & 0.00\end{array}$

Uncertain political support

Future political support for electric cars is very uncertain in Denmark/Sweden.

$90.1 \% \quad 54.6 \% \quad * * * \quad 0.19 \quad 64.3 \% \quad 48.2 \% \quad * * * \quad 0.02$

The development of public incentives for electric

cars is very unpredictable in Denmark/Sweden.

$\begin{array}{llllllll}86.0 \% & 56.1 \% & * * * & 0.14 & 56.7 \% & 47.0 \% & * * * & 0.01\end{array}$

The resale value of electric cars is very

unpredictable. $^{\mathrm{d}}$

$\begin{array}{lllllll}53.0 \% & 27.1 \% & * * * & 0.12 & 42.4 \% & 46.1 \% & 0.00\end{array}$

Intention

\begin{tabular}{llllllll}
\hline My next car will be an electric car. & $90.9 \%$ & $94.6 \%$ & $* * *$ & 0.01 & $20.7 \%$ & $29.4 \%$ & 0.00
\end{tabular}

If I had an electric car and a normal car available,

I would mainly use the electric car.

$97.9 \% \quad 98.0 \% \quad * \quad 0.00 \quad 57.7 \% \quad 62.7 \% \quad 0.00$

Notes. "Percentages of people who "agree" or "totally agree" to the respective item.

${ }^{b}$ Different formulation for BEV and ICEV users. ${ }^{\mathrm{c}}$ The item was recoded when creating a mean scale.

${ }^{\mathrm{d}}$ This item is not included in the mean scale as it led to a too low internal consistency.

*significant in ANOVA: $\mathrm{p}<.05 ; * * \mathrm{p}<.001 ; * * * \mathrm{p}<.001$.

Based on the allocation of items to the factors as shown in Table 3, six mean scales were calculated. With Cronbach's alpha above .7 (mostly above .8), all factors have acceptable internal consistencies and were used for comparisons across user groups, waves and countries. Figure 2 shows how BEV users in Denmark and Sweden differ on the six attitudinal scales in the three waves of the data collection. We found that Swedes perceive lower barriers towards BEV usage than Danes do. However, this refers mostly to the first two waves where the sampling was less comparable. In wave 3, differences between Denmark and Sweden are not remarkable, except for the 
perceived uncertainty about political support for BEVs, which is perceived significantly lower in Sweden than in Denmark $(\mathrm{p}<.001)$ as already shown on itemlevel in Table 4. Figure 3 shows the respective results for Danish and Swedish ICEV users. The comparison of Figure 2 and Figure 3 illustrates that ICEV users significantly differ from BEV users with regard to all dimensions $(\mathrm{p}>.001)$. Similar to BEV users, differences between ICEV users in Denmark and Sweden are more pronounced for wave 1, where the two samples were less comparable (Figure 3). For wave 3, the most remarkable difference is the uncertainty about political support. While this difference is larger among BEV users, it is also significant for ICEV users $(\mathrm{p}<.001)$.

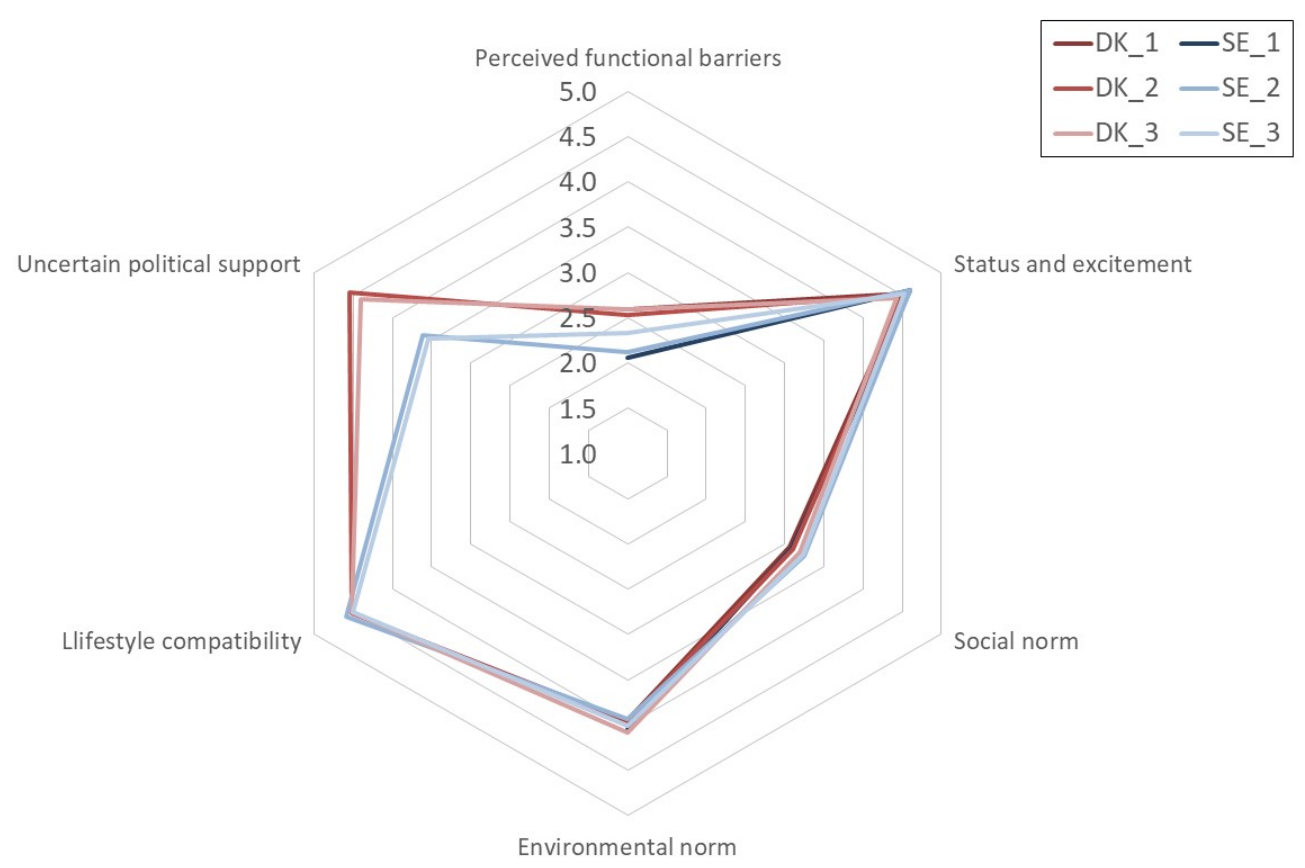

Figure 2: Attitudinal factors in relation to BEV s assessed by BEV users in DK and SE (wave 1-3); $1=$ low expression; 5 = higher expression based on a 5-point agreement scale 


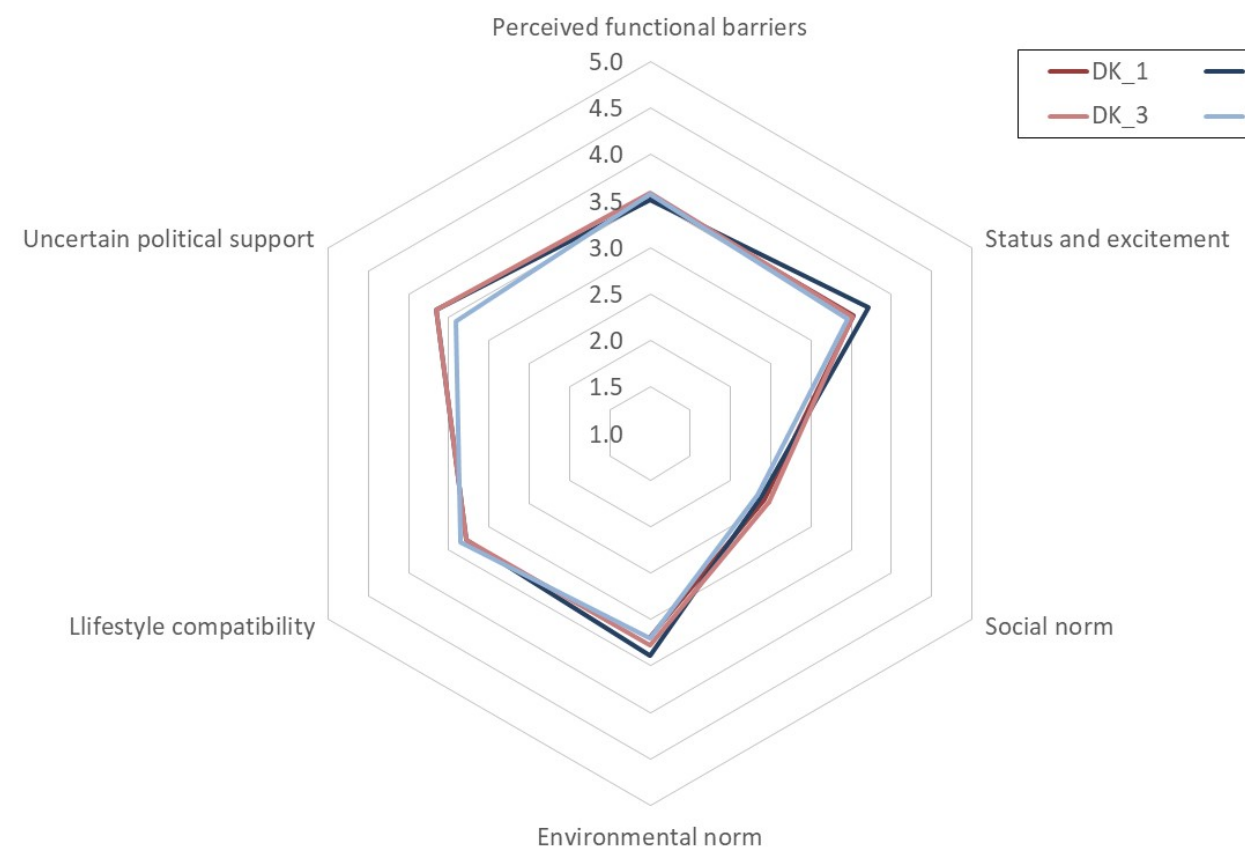

Figure 3: Attitudinal factors in relation to BEVs assessed by ICEV users in DK and SE (wave 1-3), $1=$ low expression; 5 = higher expression based on a 5-point agreement scale

Both BEV users and ICEV users were asked to evaluate how important different economic and functional aspects were for their actual and potential BEV purchase, and how satisfying they assess the different aspects. Results are shown separately for BEV (Figure 4) and ICEV users (Figure 5). When looking at BEV users, driving range, the number of fast chargers along the highway network and environmental performance are the aspects that BEV users evaluate as most important. The largest discrepancies between satisfaction and importance are found for the purchase price, public incentives and chargers along the highway network - in all cases the differences are significant $(\mathrm{p}<.001)$ both in Denmark and Sweden, indicating a desire for further improvements in these aspects. Less need for action indicated by non-significant discrepancies of satisfaction and importance is seen in both countries 
for maintenance costs; in Sweden additionally for chargers where people live and work $(\mathrm{p}>.10)$.

When comparing Danish and Swedish BEV users, the largest discrepancy is found in the satisfaction with public incentives $(\mathrm{p}<.001)$, the aspect with which Danes are the least satisfied. Another remarkable difference between both countries is that Danes put more emphasis on the driving range compared to Swedes $(\mathrm{p}<.001)$ and at the same time are less satisfied $(\mathrm{p}<.001)$.

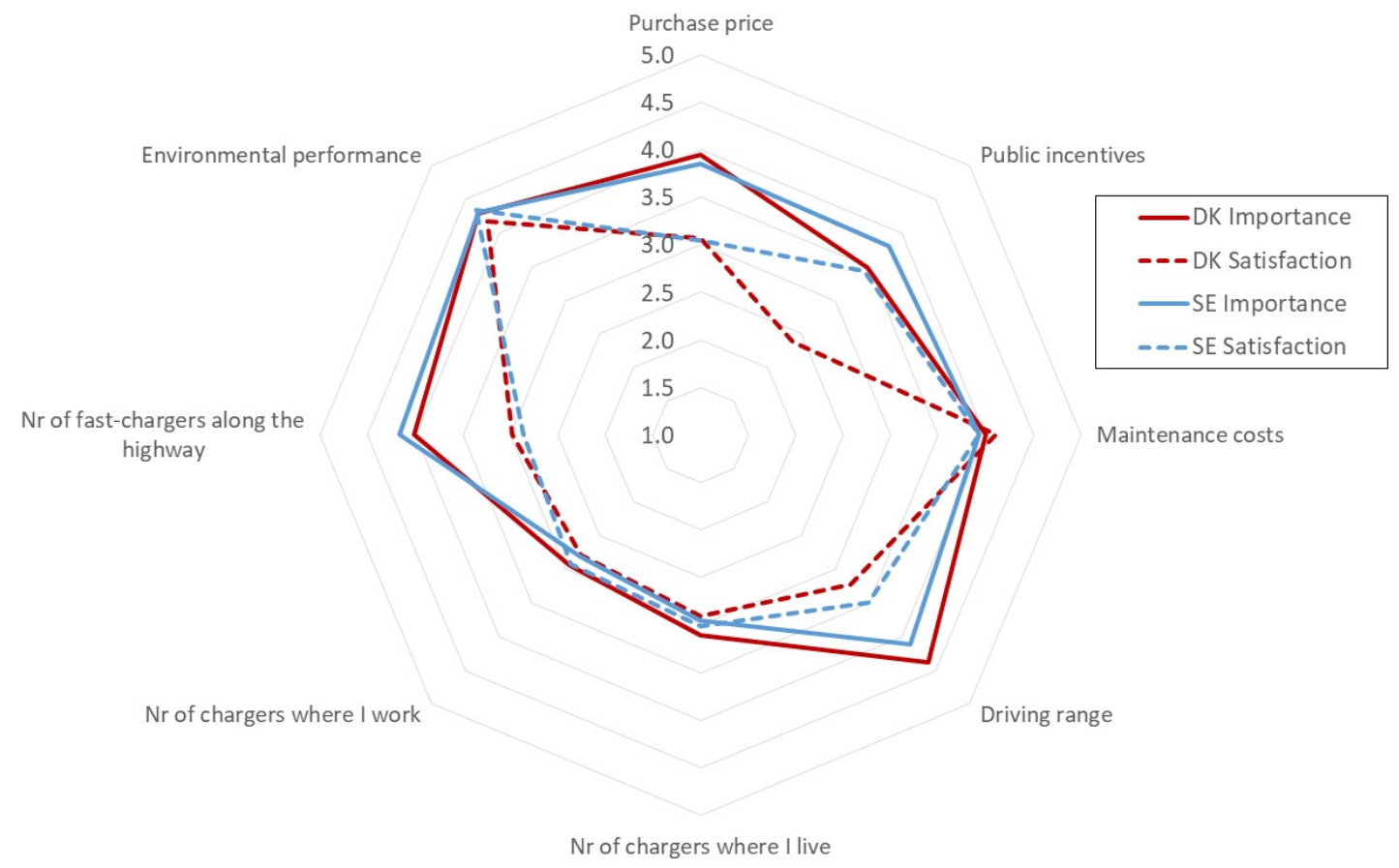

Figure 4: Importance and satisfaction: Assessment of BEV characteristics in DK and SE (wave 3, BEV users); 1 =not important/not satisfying; 5 = very important/very satisfying based on a 5-point scale.

For ICEV users (Figure 5), there are great and significant $(\mathrm{p}<.001)$ discrepancies for all characteristics in both countries, in particular for the purchase price and for the number of chargers where people live. When interpreting these results, it has to be taken into account that "don't know" answers are not included in the analysis but 
treated as missing. Yet, in particular ICEV users often felt unable to evaluate the different BEV characteristics, in particular with regard to the number of chargers along the motorway (DK: 43.6\%; SE: 33.1\%), "maintenance costs" (DK: 35.1\%; SE: 32.1\%), and "chargers where I work" (DK: 36.5\%; SE: 28.3\%). This indicates a clear information deficit that should be addressed in promotional activities, especially in case of low maintenances costs, a clear advantage of BEVs, as well as for any improvements in charging infrastructure.

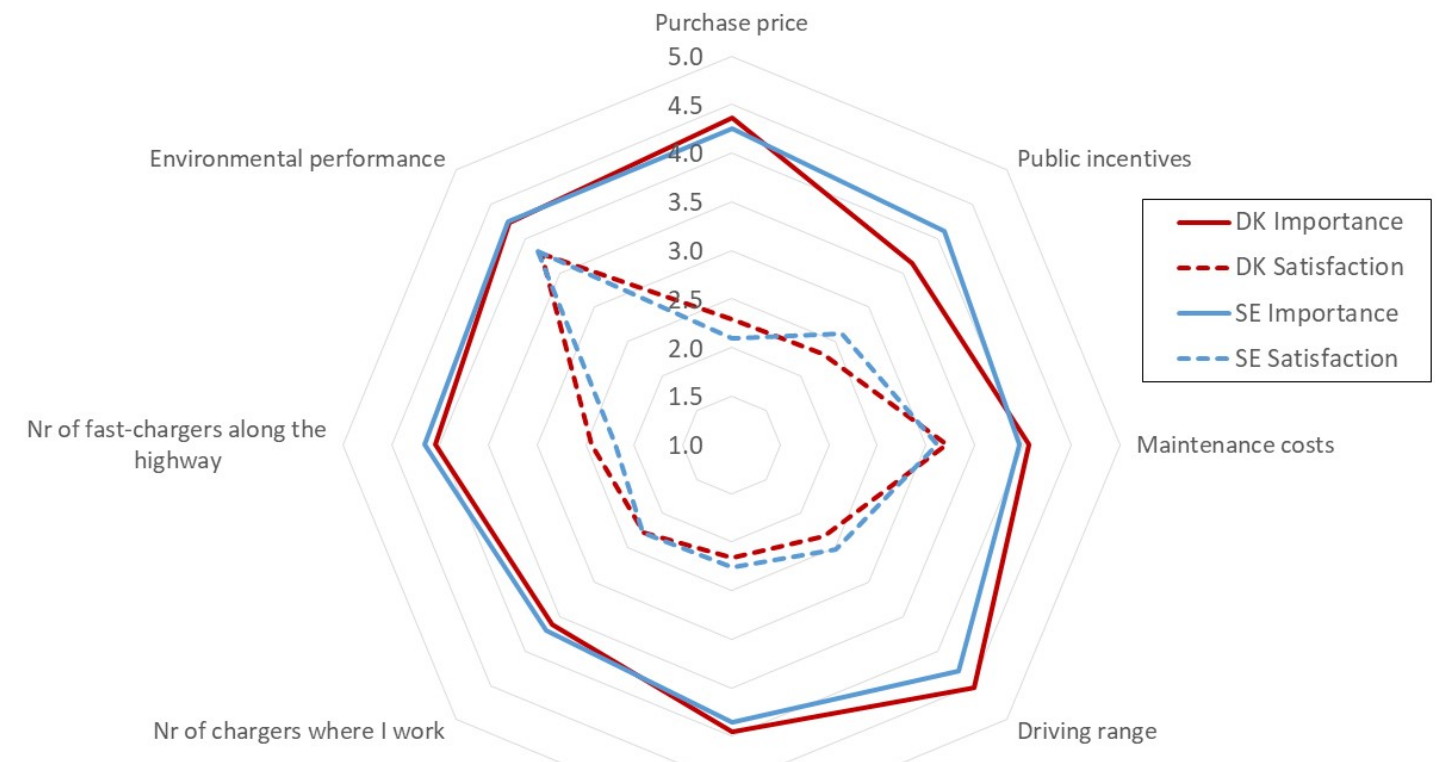

$\mathrm{Nr}$ of chargers where I live

Figure 5: Importance and satisfaction: Assessment of BEV characteristics in DK and SE (wave 3, ICEV users); I=not important/not satisfying; $5=$ very important/very satisfying based on a 5-point scale

Changes between waves are in most cases not very pronounced, however, some significant $(\mathrm{p}<.001)$ differences with a bit higher effect sizes $\left(\mathrm{Eta}^{2}=.03\right)$ are worth mentioning: In Denmark, BEV users were more satisfied with public incentives in wave $3(M=2.4)$ than in wave $1(M=1.9)$ and wave $2(M=2.0)$, though the satisfaction 
is still comparably low. Danish ICEV users became a bit more satisfied with maintenance costs from wave $1(\mathrm{M}=3.0)$ to wave $3(\mathrm{M}=3.2)$, probably indicating a success in providing knowledge about low maintenance costs of BEVs. In Sweden, BEV users were also more satisfied with public incentives in wave $3(M=3.4)$ compared to wave $1(\mathrm{M}=3.0)$ and wave $2(\mathrm{M}=3.1)$. However, they became less satisfied with environmental performance $(M=4.3$ in wave 3 vs. $M=4.7$ in wave 1), which is also observed in Denmark $(M=4.2$ in wave 3 vs. $M=4.5$ in wave 1$)$, just on a bit lower level. Possible explanations are higher expectations with regard to environmental performance and perhaps, also, critical media discussion about battery production and non-environmentally-friendly energy sources.

\subsection{BEV usage for cross-border trips}

For all car types in the household, we asked whether the car was used to travel to other countries in the past 5 years. As Figure 6 shows, a higher percentage of respondents both in Denmark and in Sweden travelled to other countries with an ICEV than with a BEV. When considering people who have both car types in the household (across waves and countries), 66\% have used the ICEV to travel to another country and $43 \%$ have used the BEV ( $p<.001$, McNemar test). When looking at changes over time, in Denmark the percentages from wave 1 to wave 3 slightly decreases for ICEV, and increases for BEVs, however, these changes are not significant $\left(\mathrm{Chi}^{2}\right.$-tests, $\left.\mathrm{p}>.10\right)$. In Sweden, the percentages go down for both car types, but the change is only significant $(p<.001)$ for ICEVs. This change is, however, likely to be related to the different sampling in both waves. The fact that Danish ICEV users made more cross-country trips than Swedes can probably be explained with the intentional overrepresentation of the Capital Region of Denmark 
(in both waves) as it lies close to the Swedish border, which invites for cross-border trips. $^{1}$

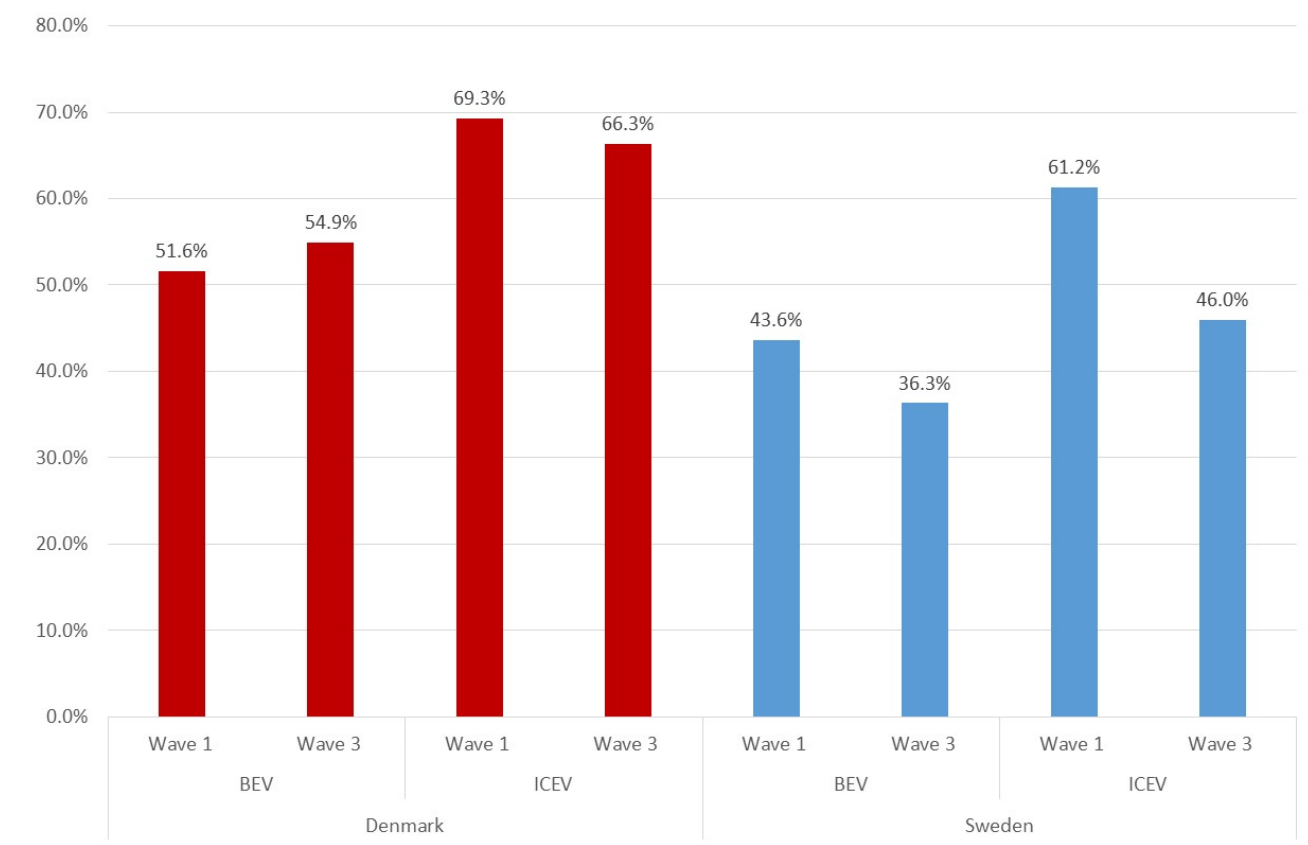

Figure 6: Percentage of respondents who reported to have used a BEV/ICEV for travelling to another country within the past 5 years (of those who have the respective car type in the household)

Much more pronounced than differences between countries and over time are differences between BEV users of different car makes: $80 \%$ of Tesla users reported travelling to another country, compared to only $31 \%$ of people using a BEV of another brand - a difference that is highly significant $\left(\mathrm{Chi}^{2}\right.$-tests, $\left.\mathrm{p}<.001\right)$. A similar difference between BEV users is found in Figenbaum and Nordbakke (2019) focusing on long distance trips.

\footnotetext{
${ }^{1}$ Between $24 \%$ and $32 \%$ of BEV users (depending on survey wave and country) who conducted a cross border trip reported to have experienced problems when trying to charge in a foreign country (no significant change over time, $p>.10$ ). The most frequently experienced problems refer to the payment solution (45\% of those experiencing problems), the number or kind of chargers (44\%), the connection to the charger (28\%), and waiting times $(14 \%)$.
} 


\subsection{Effect assessment of GREAT activities on purchase intention and BEV use}

BEV users in Denmark and Sweden in waves 2 and 3 were provided with a list of all existing (up to that point of time) GREAT chargers and asked which ones they have seen and/or used. The number of GREAT chargers a person has seen and/or used was used as an independent variable in a linear regression to model purchase intention while controlling for relevant other factors such as demographics, and BEV mileage as shown in Table 5 (Model 1). In Denmark, the variable "number of GREAT chargers a person has seen and/or used" ranges from 0 to 8 and in Sweden from 0 to 34. The highest number corresponds to the number of chargers that have been installed and put in use when collecting data in wave 3. In Denmark, $32 \%$ of the sample was aware of at least one new GREAT fast charger (without necessarily having used it), and 25\% have used at least one of the new chargers. In Sweden the corresponding figures are $41 \%$ and $50 \%$, respectively. While we found a very small but significant effect of the number of GREAT chargers that people are aware of in Denmark $($ Beta $=0.1 ; p<.001)$, in Sweden the variable did not reach significance $(p$ $=.054)$.

All in all, the two models only explain a very limited amount of variance of the purchase intention in Denmark and Sweden. However, the explained variance increases considerably, when adding the attitudinal factors, which are all significant, except for the perceived political support in Sweden (see Model 2). In Denmark, perceived uncertainty about political support is significant but not in the expected direction, meaning that the more uncertainty people express, the more likely they are to buy a BEV (again). This may indicate that people who express uncertainty are in particular people who intend to buy a BEV but await more policy support. The strongest factors in both countries are lifestyle comparability and symbolic-affective 
attitudes (status and excitement) towards BEVs. The relevance of these psychological factors should be taken into account in any efforts to encourage current BEV users buying a BEV again. 
Table 5: Linear regression analysis modelling BEV users' purchase intention in

Denmark and Sweden (wave 2 and 3)

\begin{tabular}{|c|c|c|c|c|c|c|c|c|}
\hline & \multicolumn{4}{|c|}{ DK } & \multicolumn{4}{|c|}{ SE } \\
\hline & \multicolumn{2}{|c|}{ Model 1} & \multicolumn{2}{|c|}{ Model 2} & \multicolumn{2}{|c|}{ Model 1} & \multicolumn{2}{|c|}{ Model 2} \\
\hline & Beta & $p$ & Beta & $p$ & Beta & $p$ & Beta & $p$ \\
\hline (Constant) & & 0.04 & & 0.00 & & 0.02 & & 0.00 \\
\hline Wave 3 & 0.06 & 0.04 & 0.08 & 0.00 & -0.04 & 0.25 & 0.00 & 0.96 \\
\hline Age & 0.35 & 0.13 & 0.10 & 0.57 & 0.59 & 0.01 & 0.37 & 0.06 \\
\hline Age (squared) & -0.34 & 0.14 & -0.04 & 0.83 & -0.58 & 0.01 & -0.37 & 0.06 \\
\hline Gender & -0.04 & 0.24 & -0.01 & 0.81 & -0.04 & 0.26 & -0.01 & 0.63 \\
\hline One-person household & -0.06 & 0.09 & -0.02 & 0.51 & -0.05 & 0.19 & -0.02 & 0.55 \\
\hline Household with children under & 0.03 & 0.48 & 0.04 & 0.20 & 0.02 & 0.66 & -0.01 & 0.73 \\
\hline 10 & & & & & & & & \\
\hline University education & -0.04 & 0.17 & -0.03 & 0.19 & -0.06 & 0.10 & -0.06 & 0.04 \\
\hline Income & -0.06 & 0.07 & -0.03 & 0.23 & -0.05 & 0.14 & -0.03 & 0.29 \\
\hline Self-employed & 0.01 & 0.74 & 0.04 & 0.12 & 0.02 & 0.54 & 0.02 & 0.56 \\
\hline $\begin{array}{l}\text { Household with more than one } \\
\text { car }\end{array}$ & -0.11 & 0.00 & -0.07 & 0.02 & -0.06 & 0.12 & -0.02 & 0.40 \\
\hline Mileage BEV & 0.13 & 0.00 & 0.05 & 0.09 & -0.01 & 0.86 & 0.01 & 0.79 \\
\hline Tesla & 0.00 & 0.94 & -0.10 & 0.00 & 0.12 & 0.00 & -0.01 & 0.82 \\
\hline $\begin{array}{l}\text { Number of GREAT chargers } \\
\text { aware of }\end{array}$ & 0.09 & 0.00 & 0.05 & 0.06 & 0.02 & 0.54 & 0.04 & 0.13 \\
\hline Status and excitement & & & 0.20 & 0.00 & & & 0.25 & 0.00 \\
\hline Perceived functional barriers & & & -0.18 & 0.00 & & & -0.20 & 0.00 \\
\hline Social norm & & & 0.08 & 0.00 & & & 0.08 & 0.01 \\
\hline Environmental norm & & & 0.16 & 0.00 & & & 0.11 & 0.00 \\
\hline Lifestyle comparability & & & 0.31 & 0.00 & & & 0.25 & 0.00 \\
\hline Uncertain political support & & & 0.07 & 0.00 & & & 0.03 & 0.29 \\
\hline $\mathrm{R}^{2}$ & & 0.05 & & 0.40 & & 0.03 & & 0.35 \\
\hline $\mathrm{R}^{2}$ adjusted & & 0.03 & & 0.39 & & 0.02 & & 0.34 \\
\hline
\end{tabular}

We used the same factors as in Table 5 to explain whether BEV users made a crossborder trip with a BEV or not by use of a logistic regression analysis (see Table 6). The by far strongest determinant of having made a cross-border trip by BEV is 
having a Tesla or not. Tesla users are about ten times more likely to have made a cross-border trip as compared to BEV users of other car makes, which is consistent with the results of previous studies (Nicholas et al., 2017; Figenbaum and Nordbakke, 2019). Awareness of GREAT chargers has a significant effect both in Denmark and Sweden, however, the effect is comparably small, especially in Sweden. In Denmark, having more than one car in the household decreases the likelihood of using a BEV for a cross-border trip. Contrary to modelling purchase intention, attitudes play a less relevant role in modelling a cross-border trip, where the inclusion of attitudinal factors does not increase the explained variance considerably (see Model 2). Not surprisingly, perceived functional barriers play the largest role among the attitudinal factors. Social norm is a significant factor in Denmark but not in Sweden. 
Table 6: Logistic regression analysis modelling whether BEV users in Denmark and

Sweden had a BEV cross-border trips within the past 5 years or not (wave 2 and 3)

\begin{tabular}{|c|c|c|c|c|c|c|c|c|}
\hline & \multicolumn{4}{|c|}{ DK } & \multicolumn{4}{|c|}{ SE } \\
\hline & \multicolumn{2}{|c|}{ Model 1} & \multicolumn{2}{|c|}{ Model 2} & \multicolumn{2}{|c|}{ Model 1} & \multicolumn{2}{|c|}{ Model 2} \\
\hline & O.R. & $p$ & O.R. & $p$ & O.R. & $p$ & O.R. & $p$ \\
\hline (Constant) & 0.00 & 0.00 & 0.03 & 0.05 & 0.05 & 0.03 & 0.09 & 0.18 \\
\hline Wave 3 & 1.07 & 0.66 & 1.05 & 0.77 & 1.15 & 0.47 & 1.24 & 0.28 \\
\hline Age & 1.18 & 0.00 & 1.16 & 0.00 & 1.03 & 0.55 & 1.02 & 0.74 \\
\hline Age squared & 1.00 & 0.00 & 1.00 & 0.00 & 1.00 & 0.58 & 1.00 & 0.79 \\
\hline Gender & 1.79 & 0.02 & 0.59 & 0.04 & 1.05 & 0.88 & 1.07 & 0.83 \\
\hline One-person household & 0.48 & 0.02 & 0.52 & 0.04 & 0.74 & 0.34 & 0.81 & 0.51 \\
\hline Household with children under 10 & 0.94 & 0.75 & 0.94 & 0.77 & 0.89 & 0.56 & 0.86 & 0.44 \\
\hline University education & 1.17 & 0.43 & 1.23 & 0.30 & 0.81 & 0.19 & 0.80 & 0.17 \\
\hline Income & 1.06 & 0.23 & 1.07 & 0.19 & 1.13 & 0.01 & 1.14 & 0.01 \\
\hline Self-employed & 1.08 & 0.70 & 1.12 & 0.60 & 0.89 & 0.54 & 0.93 & 0.72 \\
\hline Household with more than one car & 0.54 & 0.00 & 0.58 & 0.00 & 0.94 & 0.74 & 0.98 & 0.93 \\
\hline Mileage BEV & 1.00 & 0.00 & 1.00 & 0.00 & 1.00 & 0.00 & 1.00 & 0.00 \\
\hline Tesla & 10.81 & 0.00 & 9.82 & 0.00 & 6.51 & 0.00 & 5.12 & 0.00 \\
\hline Number of GREAT chargers aware of & 1.24 & 0.00 & 1.22 & 0.00 & 1.07 & 0.00 & 1.07 & 0.00 \\
\hline Status and excitement & & & 0.68 & 0.06 & & & 1.15 & 0.50 \\
\hline Perceived functional barriers & & & 0.57 & 0.00 & & & 0.65 & 0.00 \\
\hline Social norm & & & 1.43 & 0.00 & & & 0.97 & 0.79 \\
\hline Environmental norm & & & 1.02 & 0.80 & & & 1.03 & 0.67 \\
\hline Lifestyle comparability & & & 1.28 & 0.15 & & & 1.04 & 0.80 \\
\hline Uncertain political support & & & 1.03 & 0.80 & & & 0.91 & 0.31 \\
\hline Nagelkerke's $\mathrm{R}^{2}$ & & 0.38 & & 0.43 & & 0.25 & & 0.27 \\
\hline
\end{tabular}

ICEV users were not asked about the awareness of specific chargers. To evaluate the effect of GREAT activities in the intention of ICEV users to buy a BEV, we included a dummy variable that indicated whether people lived in a municipality where a Drive Clean event had taken place before their survey participation. Again, we 
controlled for demographic variables (see Table 7, Model 1) and in Model 2, we included attitudinal factors to show their effect on purchase intention of ICEV users. For the effect assessment, however, Model 1 is the relevant one to consider as attitudinal factors are also expected to change through the Drive Clean events, thus parts of the effect will be taken away when including the Drive Clean events in the model. As our analyses of ICEV users are based on waves 1 and 3, we could not include "uncertain political support" in the model, as the related items were not included in wave 1 .

Results show that Drive Clean events did not have a significant effect in Denmark, while the effect is significant in Sweden, even though it is small. When interpreting the country differences, one has to take into account that Drive Clean events in Denmark took place later, so that there was less time to change purchase intentions. In addition, in Denmark the events often took place in larger cities, where probably a lower percentage of inhabitants got aware of them compared with events in the smaller Swedish cities. While we again see that only a limited amount of variance can be explained by demographic factors, the picture changes when attitudinal factors are considered. In both countries, symbolic-affective attitudes (status and excitement) show the highest effect, followed by lifestyle comparability and social norm. Perceived functional barriers have a higher effect in Sweden than in Denmark. 
Table 7: Linear regression analysis modelling ICEV users' purchase intention in

Denmark and Sweden (wave 2 and 3)

\begin{tabular}{|c|c|c|c|c|c|c|c|c|}
\hline & \multicolumn{4}{|c|}{ DK } & \multicolumn{4}{|c|}{$\mathbf{S E}$} \\
\hline & \multicolumn{2}{|c|}{ Model 1} & \multicolumn{2}{|c|}{ Model 2} & \multicolumn{2}{|c|}{ Model 1} & \multicolumn{2}{|c|}{ Model 2} \\
\hline & Beta & $p$ & Beta & $p$ & Beta & $p$ & Beta & $p$ \\
\hline (Constant) & & 0.02 & & 0.00 & & 0.66 & & 0.00 \\
\hline Wave 3 & 0.15 & 0.00 & 0.10 & 0.00 & -0.09 & 0.00 & 0.05 & 0.02 \\
\hline Age & -0.14 & 0.51 & -0.24 & 0.09 & -0.10 & 0.57 & 0.05 & 0.68 \\
\hline Age (squared) & 0.06 & 0.79 & 0.21 & 0.15 & 0.02 & 0.91 & -0.08 & 0.50 \\
\hline Gender & -0.09 & 0.00 & -0.05 & 0.01 & -0.20 & 0.00 & -0.07 & 0.00 \\
\hline One-person household & -0.04 & 0.20 & 0.00 & 0.91 & -0.06 & 0.03 & -0.03 & 0.11 \\
\hline $\begin{array}{l}\text { Household with } \\
\text { children under } 10\end{array}$ & 0.04 & 0.27 & 0.01 & 0.73 & 0.07 & 0.03 & 0.01 & 0.62 \\
\hline University education & 0.17 & 0.00 & 0.08 & 0.00 & 0.06 & 0.05 & 0.01 & 0.42 \\
\hline Income & -0.01 & 0.69 & 0.00 & 0.88 & 0.03 & 0.23 & 0.01 & 0.67 \\
\hline Self-employed & 0.02 & 0.43 & 0.02 & 0.32 & 0.12 & 0.00 & 0.06 & 0.00 \\
\hline $\begin{array}{l}\text { Household with more } \\
\text { than one car }\end{array}$ & -0.06 & 0.04 & 0.02 & 0.31 & -0.07 & 0.01 & 0.00 & 0.97 \\
\hline Drive Clean event & 0.03 & 0.38 & 0.01 & 0.58 & 0.06 & 0.03 & 0.01 & 0.65 \\
\hline Status and excitement & & & 0.34 & 0.00 & & & 0.41 & 0.00 \\
\hline $\begin{array}{l}\text { Perceived functional } \\
\text { barriers }\end{array}$ & & & -0.08 & 0.00 & & & -0.19 & 0.00 \\
\hline Social norm & & & 0.22 & 0.00 & & & 0.18 & 0.00 \\
\hline Environmental norm & & & 0.14 & 0.00 & & & 0.09 & 0.00 \\
\hline Lifestyle comparability & & & 0.25 & 0.00 & & & 0.18 & 0.00 \\
\hline $\mathrm{R}^{2}$ & & 0.06 & & 0.55 & & 0.11 & & 0.64 \\
\hline $\mathrm{R}^{2}$ adjusted & & 0.05 & & 0.55 & & 0.10 & & 0.63 \\
\hline
\end{tabular}

Another relevant result is that purchase intention in Denmark increased significantly from wave 1 to wave 3. This is not the case in Sweden (it is actually the opposite), which can probably be attributed to the more representative sample in wave 3 . This 
interpretation is supported by the change of sign in the coefficient when attitudinal factors are included, indicating that purchase intention also increased in Sweden when we control for the different attitudes in the sample.

\section{Conclusions and policy implications}

In this study, we examined recent changes in the acceptance and use of BEVs in Denmark and Sweden and identified factors related to the acceptance. We focused on both BEV and ICEV users.

Overall, we can conclude that the changes we observed in the two-years-period are not very pronounced. In Denmark, we found a marginal increase in cross-border trips with BEVs, as well as a minor increase in purchase intention. We also found that the uncertainty about political support for BEV became a bit lower in both countries. However, in Denmark the perceived uncertainty about political support is still significantly higher than in Sweden - both for BEV and ICEV users. Danes also perceive more functional barriers towards BEV use than Swedes. In both countries and for both user groups these perceived barriers are significantly related to purchase intention and to making a cross-border trip with a BEV or not. In case of crossborder trips, by far the most important factor is the car make. Tesla users are much more likely to make a cross-border trip than BEV users of other car makes, even when income and other potentially relevant variables are controlled for. At the time of the data collection, only Tesla models provided driving distances longer than 300 $\mathrm{km}$ on a fully charged battery ${ }^{2}$. A reason for this result, therefore, is most probably that BEV users do not find it comfortable to drive long distances in BEVs unless this threshold is fulfilled, which is consistent with previous studies (Nicholas, Tal and

\footnotetext{
${ }^{2}$ In Denmark, the Hyundai Kona 64kWh model was introduced in November 2018 and only very few vehicles were delivered in January 2019 where wave 3 data collection was conducted.
} 
Turrentine, 2017). However, a relevant factor could also be the access to a large network of Tesla fast chargers, only accessible for Tesla models. This stresses that a further expansion of the fast charging network is a relevant factor for increasing the use of BEVs for long-distance trips. This conclusion is supported by the high importance BEV users place to the number of chargers along highways and the low satisfaction about the current status.

We also found empirical support for the effect of the newly built charging infrastructure, which was set up as part of the EU project GREAT, both on the conduction of cross-border trips and on purchase intention. However, in case of purchase intention, we could only show this effect in Denmark. A reason for that could be that the fast charge network in Sweden is already extended compared to Denmark and thus the additional effect of the GREAT chargers was only marginal. However, in Sweden we found a significant effect of Drive Clean events on ICEV users' intention to purchase a BEV. The fact that we did not find this effect in Denmark is probably related to the timing and location of events. In Denmark, Drive Clean events were conducted later in the project and in larger cities than in Sweden, so the effect on a single citizen maybe lower due to lower awareness. The result that overall effects related to information provision are small and partly insignificant is in line with previous research showing that positive information (as provided in the Drive Clean events) have less impact on EV purchase intention than negative information (Cherchi, 2017). While the impact of negative information is difficult to address in information campaigns, these should "correctly inform users about all the positive (or no-negative) experiences with EV" (Cherchi, 2017).

With regard to the assessment of the satisfaction and importance of the different BEV attributes, not only did we find strong differences between BEV and ICEV 
users but we also found a great lack of knowledge among ICEV users, where a high percentage felt unable to assess these aspects. Based on a high discrepancy in the assessment of the importance and satisfaction, BEV users see a strong need for action in the increase of chargers along the highway network, while for ICEV users an increase in the number of chargers where they live and work represents a higher need. This probably indicates that existing BEV users have good conditions to charge at home and work, and thus see more need in network extension, while ICEV users focus more on basic needs, or do not have a clear perception of their needs. In both countries and user groups, a strong need for action was observed with regard to purchase price and political support, which resembles insights from expert interviews in the Nordic countries that stress the need for "strong stable national targets and price incentives" (Kester et al., 2018). Regarding the assessment over time, we found that ICEV users rated the maintenance costs more positively at the end (wave 3) than at the beginning of the study (wave 1), possibly showing an effect of public awareness campaigns and other forms of knowledge distribution. The different level of knowledge within the sample can be considered as a limitation for the "correct" assessment of BEV attributes. However, for purchase intention, we consider customers' expectations more relevant than objective factors, as long as people are not aware of them. Another limitation is the difference in the sampling strategies adopted, which reduced the comparability of samples between countries and over time. We addressed this limitation when we discussed the descriptive results, while we compensated for the problem by controlling for several demographic factors in the regression models.

All in all, we can conclude that efforts to increase BEV uptake show an effect but much more has to be done. Probably information should be provided via campaigns 
that better trigger symbolic and affective motives - something the car industry extensively does when advertising ICEVs (Hunecke and Baasch, 2007; Wells and Xenias, 2015), while it seems that this potential has so far not been exhausted when advertising BEVs. A reason for this could be that promoting the fun of driving BEVs due to its fast acceleration and game-like breaking experience (Labeye et al., 2016) may conflict with the image of being a green and responsible driver that most BEV users identify with (Ingeborgrud and Ryghaug, 2019; Skippon and Garwood, 2011). However, promoting driving excitement related to BEVs may be a way to win new customer groups including car enthusiasts (e.g. Morton et al., 2017), and people who dislike a green driving identity (Graham-Rowe et al., 2012). Generally, it can be expected that marketing strategies tailored to specific customer profiles are more effective than one-fits-all approaches (Haustein and Hunecke, 2013; Klöckner et al., 2015; Priessner et al., 2018). Allowing customers to try BEVs, maybe for a longer period than a short test drive, might be a simple strategy to raise awareness about enjoyable driving characteristics. Noel et al. (2019) found across five Nordic countries that people who had previously driven a BEV had higher BEV preferences. In case of environmental marketing, one should avoid promoting BEVs as the most eco-friendly transport solution. In particular in urban traffic, walking, cycling and public transport are better alternatives than any form of car traffic due to its higher use of space and resources (Mattioli et al., 2020). When providing public incentives like free parking for BEVs in cities or allowing the use of bus lanes, one should consider potential shifts from green transport modes to car use. Generally, when promoting BEVs as environmentally friendly, potential rebound and negative spillover effects should be taken into account. When people get the impression that BEV use and purchase is not environmentally harmful, this can lead to increased 
driving (Fujii, 2010), feeling less morally obliged to reduce car use (Haustein \& Jensen, 2018; Klöckner et al., 2013; Langbroek et al., 2017) and/or feeling licensed to invest more in other energy-intense goods and activities, such as long-distance vacation (Sorrell et al., 2020). It is, however, also possible that a green identity as a BEV owner spills over to other areas of consumption or vice versa as indicated by Chen et al. (2020) who found electric vehicle adoption intention related to other sustainability preferences and activities. This stresses the need to examine the interactions of behaviours in different areas of consumptions in more detail and the circumstances under which positive spillover effects can be achieved and negative ones can be avoided.

We found that scepticism over the environmental performance of BEVs has slightly increased during the project period, probably because of the uptake of environmental aspects of battery production and/or the use of non-renewable energy sources for BEV use in the media. This makes it even more important to inform about the environmental benefits of different transport solutions based on scientific evidence, in a clear and understandable way avoiding current misinformation about EV performance (Cherchi, 2017).

Based on our findings, we can conclude that the following three aspects need to be addressed to increase BEV adoption: First, the fast charging network needs to be expanded. The charging network that Tesla provides for its customers may serve as a successful example and might play a crucial role in Tesla owners' higher percentage of cross-border trips by BEVs. Second, clear and long-term policy signals are required to support people in their purchase decision and make them trust that BEVs have a future. Here, people in Denmark show a higher level of uncertainty than Swedes, probably because of many changes in the recent years, which left potential 
customers confused. Finally, tailored marketing to potential user groups with a higher focus on environmental aspects ("green drivers") versus technology innovation and driving fun ("car enthusiasts") is required in combination with the provision of correct and understandable information to avoid rebound and negative spillover effects. 


\section{Acknowledgments}

We acknowledge financial support from the EU project GREAT - Green Region for Electrification and Alternative fuels for Transport (2014-EU-TM-0477-S) as part of the Trans-European Transport Network (TEN-T). In addition, we thank all GREAT partners for comments on the questionnaire and/or support of the data collection, in particular Britt Karlsson Green and Jonas Brantefors from Region Skåne, Christian Halleløv and Mette Marie Knudsen from E.ON Denmark and Mattias Vendel from E.ON Sweden. 


\section{References}

Axsen, J., Langman, B. and Goldberg, S. (2017) 'Confusion of innovations: Mainstream consumer perceptions and misperceptions of electric-drive vehicles and charging programs in Canada', Energy Research \& Social Science, 27, pp. 163-173. doi: 10.1016/J.ERSS.2017.03.008.

Bailey, J. and Axsen, J. (2015) 'Anticipating PEV buyers' acceptance of utility controlled charging', Transportation Research Part A: Policy and Practice, 82, pp. 29-46. doi: 10.1016/J.TRA.2015.09.004.

Caperello, N., Kurani, K. S. and TyreeHageman, J. (2015) 'I Am Not An Environmentalist Wacko!Getting From Early Plug-in Vehicle Owners to Potential Later Buyers', in Transp. Res. Board Annu. Mee.

Chen, C. F., de Rubens, G. Z., Noel, L., Kester, J., \& Sovacool, B. K. (2020). Assessing the socio-demographic, technical, economic and behavioral factors of Nordic electric vehicle adoption and the influence of vehicle-to-grid preferences. Renewable and Sustainable Energy Reviews, 121, 109692.

Cherchi, E. (2017) 'A stated choice experiment to measure the effect of informational and normative conformity in the preference for electric vehicles', Transportation Research Part A: Policy and Practice, 100, pp. 88-104. doi: 10.1016/J.TRA.2017.04.009.

Dansk Elbil Alliance (2019) www.danskelbilalliance.dk, Statistik. Available at: https://www.danskelbilalliance.dk/statistik (Accessed: 6 September 2019).

Dugale, M. (2018). European countries banning fossil fuel cars and switching to electric. Available at: https://www.roadtraffictechnology.com/features/european-countries-banning-fossil-fuel-cars/ (Accessed: 11.11.2019) 
DTU and DEA, (2019). Sådan skaber Danmark grøn infrastruktur til én million elbiler: analyse og anbefalinger fra DEA og DTU, November 2019. Available at:

https://www.danskelbilalliance.dk/sites/danskelbilalliance.dk/files/media/doku menter/2019-

11/Danmarks_behov_for_ladeinfrastruktur_analyse_anbefalinger.pdf (Accessed: 20.08.2020)

Egnér, F. and Trosvik, L. (2018). 'Electric vehicle adoption in Sweden and the impact of local policy instruments', Energy Policy, 121, pp. 584-596.

Figenbaum, E. and Kolbenstvedt, M. (2016) Learning from Norwegian Battery Electric and Plug-in Hybrid Vehicle users: Results from a survey of vehicle owners. Available at: https://www.toi.no/getfile.php?mmfileid=43161.

(Accessed: 11.11.2019)

Figenbaum, E. and Nordbakke, S. (2019) Battery electric vehicle user experiences in Norway's maturing market. Available at: https://www.toi.no/getfile.php?mmfileid=50956. (Accessed: 11.11.2019)

Franke, T. et al. (2012) 'Enhancing sustainability of electric vehicles: A field study approach to understanding user acceptance and behavior', in Dorn, L. and Sullman, M. (eds) Advances in Traffic Psychology.

Franke, T. and Krems, J. F. (2013) 'Understanding charging behaviour of electric vehicle users', Transportation Research Part F: Traffic Psychology and Behaviour, 21, pp. 75-89. doi: 10.1016/j.trf.2013.09.002.

Fujii, S. (2010) 'Does purchasing an "eco-car" increase the vehicle distance travelled?', in Abstracts of the 27th International Congress of Applied Psychology. 
Gärling, A. and Johansson, A. (1998) An EV in the family. Chalmers University of Technology, Department of Road and Traffic Planning, Göteborg.

Gebhardt, L. et al. (2016) 'Intermodal Urban Mobility: Users, Uses, and Use Cases', Transportation Research Procedia, 14, pp. 1183-1192. doi: 10.1016/j.trpro.2016.05.189.

Graham-Rowe, et al. (2012) 'Mainstream consumers driving plug-in battery-electric and plug-in hybrid electric cars: A qualitative analysis of responses and evaluations', Transportation Research Part A: Policy and Practice, 46(1), pp.140-153.

Hardman, S. et al. (2018) 'A review of consumer preferences of and interactions with electric vehicle charging infrastructure', Transportation Research Part D: Transport and Environment, 62, pp. 508-523. doi: 10.1016/J.TRD.2018.04.002.

Haustein, S. and Jensen, A. F. (2018) 'Factors of electric vehicle adoption: A comparison of conventional and electric car users based on an extended theory of planned behavior', International Journal of Sustainable Transportation. Taylor \& Francis, 12(7), pp. 484-496. doi: 10.1080/15568318.2017.1398790.

Haustein, S. and Hunecke, M. (2013). 'Identifying target groups for environmentally sustainable transport: assessment of different segmentation approaches', Current Opinion in Environmental Sustainability, 5(2), pp. 197-204.

Hjorthol, R. (2013) Attitudes, ownership and use of electric vehicles - a review of literature. Oslo. Available at: https://www.toi.no/getfile.php/1332442/Publikasjoner/TØI rapporter/2013/1261-2013/1261-hele rapporten nett.pdf. 
Hunecke, M. and Baasch, S. (2007). 'Inhaltsanalyse von Werbung und Artikeln zur Mobilität.’ In: Hunecke, M., Beckmann K. J. and A. Langweg (eds) Symbolisch-emotionales Marketing für den ÖPNV-Nutzerorientierte Maßnahmen zur Gestaltung und Kommunikation (pp. 55-60). Düsseldorf: ALBA Fachverlag.

IEA Global EV Outlook 2016. Beyond one million electric cars https://www.iea.org/publications/freepublications/publication/Global_EV_Outl ook_2016.pdf(Assessed November 2019)'

Ingeborgrud, L. and Ryghaug, M. (2019) 'The role of practical, cognitive and symbolic factors in the successful implementation of battery electric vehicles in Norway', Transportation Research Part A: Policy and Practice, 130, pp. 507516.

IPCC (2014) Climate Change 2014: Synthesis Report. Contribution of Working Groups I, II and III to the Fifth Assessment Report of the Intergovernmental Panel on Climate Change. Edited by R. K. Pachauri and L. A. Meyer. Geneva, Switzerland.

Jensen, A. F. (2014) Assessing the impact of direct experience on individual preferences and attitudes for electric vehicles, PhD Thesis, Technical University of Denmark, DTU DK-2800 Kgs. Lyngby, Denmark. Technical University of Denmark.

Jensen, A. F., Cherchi, E. and Mabit, S. L. (2013) 'On the stability of preferences and attitudes before and after experiencing an electric vehicle', Transportation Research Part D: Transport and Environment, 25, pp. 24-32. doi: http://dx.doi.org/10.1016/j.trd.2013.07.006.

Jensen, A. F., Cherchi, E. and Ortúzar, J. de D. (2014) ‘A long panel survey to elicit 
variation in preferences and attitudes in the choice of electric vehicles', Transportation, 41(5), pp. 973-993.

Jensen, A. F. and Mabit, S. L. (2017) 'The use of electric vehicles: A case study on adding an electric car to a household', Transportation Research Part A: Policy and Practice, 106. doi: 10.1016/j.tra.2017.09.004.

Jensen, A.F., Rasmussen, T.K. and Prato, C.G. (2020) 'A route choice model for capturing driver preferences when driving electric and conventional vehicles', Sustainability, 12, 1149.

Kester, J., Noel, L., de Rubens, G. Z., \& Sovacool, B. K. (2018). Policy mechanisms to accelerate electric vehicle adoption: a qualitative review from the Nordic region. Renewable and Sustainable Energy Reviews, 94, 719-731

Klöckner, C. A. (2015) 'Target Group Segmentation - Why Knowing Your Audience Is Important", In: Klöckner, C. A. (ed), The Psychology of Pro-Environmental Communication: Beyond Standard Information Strategies." (pp. 146-160). Palgrave Macmillan.

Klöckner, C. A., Nayum, A. and Mehmetoglu, M. (2013) 'Positive and negative spillover effects from electric car purchase to car use', Transportation Research Part D: Transport and Environment, 21, pp. 32-38. doi: 10.1016/j.trd.2013.02.007.

Krause, R. M. et al. (2013) 'Perception and reality: Public knowledge of plug-in electric vehicles in 21 U.S. cities', Energy Policy, 63, pp. 433-440. doi: 10.1016/J.ENPOL.2013.09.018.

Labeye, E. et al. (2016) 'The electric vehicle: A new driving experience involving specific skills and rules', Transportation Research Part F: Traffic Psychology and Behaviour, 37, pp. 27-40. doi: 10.1016/J.TRF.2015.11.008. 
Lane, B. and Potter, S. (2007) 'The adoption of cleaner vehicles in the UK: exploring the consumer attitude-action gap', Journal of Cleaner Production, 15(11-12), pp. 1085-1092. doi: 10.1016/J.JCLEPRO.2006.05.026.

Langbroek, J. H. M., Franklin, J. P. and Susilo, Y. O. (2017) 'Electric vehicle users and their travel patterns in Greater Stockholm', Transportation Research Part D: Transport and Environment, 52, pp. 98-111. doi: 10.1016/J.TRD.2017.02.015.

Liao, F., Molin E. and van Wee (2017) 'Consumer preferences for electric vehicles: a literature review', Transport Reviews, 33, pp. 252-275,

Mattioli, G., Roberts, C., Steinberger, J.K. and Brown, A., 2020. 'The political economy of car dependence: A systems of provision approach', Energy Research \& Social Science, 66, DOI: 10.1016/j.erss.2020.101486

Morton, C., Anable, J. and Nelson, J. D. (2017). 'Consumer structure in the emerging market for electric vehicles: Identifying market segments using cluster analysis', International Journal of Sustainable Transportation, 11(6), pp. 443459.

Nayum, A., Klöckner, C. A. and Mehmetoglu, M. (2016) 'Comparison of sociopsychological characteristics of conventional and battery electric car buyers', Travel Behaviour and Society, 3, pp. 8-20. doi: 10.1016/J.TBS.2015.03.005.

Nicholas, M. A. and Tal, G. (2017) 'Transitioning to longer range battery electric vehicles: Implications for the market, travel and charging'. SAE International.

Nicholas, M. A., Tal, G. and Turrentine, T. S. (2017) Advanced plug-in electric vehicle travel and charging behavior interim report. Available at: https://phev.ucdavis.edu/wp-content/uploads/2017/08/25.-Advanced-Plug-inElectric-Vehicle-Travel-and-Charging-Behavior-Interim-Report-.pdf. 
Noel, L., Carrone, A. P., Jensen, A. F., de Rubens, G. Z., Kester, J., \& Sovacool, B. K. (2019). Willingness to pay for electric vehicles and vehicle-to-grid applications: a Nordic choice experiment. Energy Economics, 78, 525-534.

Noel, L., de Rubens, G. Z., Kester, J., \& Sovacool, B. K. (2020). Understanding the socio-technical nexus of Nordic electric vehicle (EV) barriers: A qualitative discussion of range, price, charging and knowledge. Energy Policy, 138, 111292.

Odeh, N., Hill, N. and Forster, D. (2013). Current and future lifecycle emissions of key "low carbon" technologies and alternatives. Final report carried out for the Committee on Climate Change (CCC). Available at: https://www.theccc.org.uk/wpcontent/uploads/2013/04/Ricardo-AEAlifecycle-emissions-low-carbontechnologies-April-2013.pdf (Accessed November 2019).

Priessner, A., Sposato, R. and Hampl, N. (2018). 'Predictors of electric vehicle adoption: An analysis of potential electric vehicle drivers in Austria', Energy Policy, 122, pp. 701-714.

Peters, A. and Dütschke, E. (2014) 'How do Consumers Perceive Electric Vehicles? A Comparison of German Consumer Groups', Journal of Environmental Policy \& Planning, 16(3), pp. 359-377. doi: 10.1080/1523908X.2013.879037.

Rauh, N., Günther, M. and Krems, J.F. (2020) 'Positive influence of practical electric vehicle driving experience and range related knowledge on drivers' experienced range stress', Transportation Research Part F: Traffic Psychology and Behaviour, 71, pp. 182-197.

Region Skåne et al. (2019) Business Models - Final Report from the Action GREAT. Available at: https://great-region.org/final-report-on-business-models/. 
Region Skåne (2020). Drive Clean. Avialable at: https://great-region.org/driveclean/.

SCB - Statistiska centralbyrån (2019) Fordonsstatistik. Available at: https://www.scb.se/hitta-statistik/statistik-efter-amne/transporter-ochkommunikationer/vagtrafik/fordonsstatistik/\#.

Schmalfuß, F., Mühl, K. and Krems, J. F. (2017) 'Direct experience with battery electric vehicles (BEVs) matters when evaluating vehicle attributes, attitude and purchase intention', Transportation Research Part F: Traffic Psychology and Behaviour, 46, pp. 47-69. doi: 10.1016/J.TRF.2017.01.004.

Skatteministeriet (2015) 'Aftale mellem regeringen (V) og Socialdemokratiet, Dansk Folkeparti og Radikale Venstreom de fremtidige afgiftsvilkår for elbiler og brændselscellebiler'. Available at: https://www.skm.dk/media/1265173/091015_aftaletekst_elbiler.pdf.

Skatteministeriet (2017) Aftale mellem regeringen (V, LA, K), Socialdemokratiet og Radikale Ven-stre om justering af aftalen om de fremtidige afgiftsvilkår for elbiler og brcendselscellebiler af 9. oktober 2015 (nye lempelser for elbiler). Denmark. Available at: https://www.regeringen.dk/publikationer-ogaftaletekster/aftaletekst-aftale-om-registreringsafgift-paa-elbiler/.

Skatteministeriet (2018) 'Regeringen vil skabe ro på elbilmarkedet med nyt lovforslag'. Available at: https://www.skm.dk/aktuelt/presse/pressemeddelelser/2018/december/regering en-vil-skabe-ro-paa-elbilmarkedet-med-nyt-lovforslag.

Skatteministeriet (2019) 'Med finanslovsforslag for 2020 gør regeringen op med urimelige særordninger og styrker grøn omstilling, miljø og sundhed', 4 October. Available at: https://www.skm.dk/aktuelt/nyheder/2019/oktober/med- 
finanslovsforslag-for-2020-goer-regeringen-op-med-urimelige-saerordningerog-styrker-groen-omstilling,-miljoe-og-sundhed.

Skippon, S. and Garwood, M. (2011) 'Responses to battery electric vehicles: UK consumer attitudes and attributions of symbolic meaning following direct experience to reduce psychological distance'. Transportation Research Part D: Transport and Environment, 16(7), pp. 525-531.

Skippon, S. M. et al. (2016) 'How experience of use influences mass-market drivers' willingness to consider a battery electric vehicle: A randomised controlled trial', Transportation Research Part A: Policy and Practice, 92, pp. 26-42. doi: 10.1016/J.TRA.2016.06.034.

Socialdemokratiet (2019) EN ET-ARSPLAN SKAL SATTE TEMPO PA DEN GRØNNE OMSTILLING. Denmark. Available at: https://www.socialdemokratiet.dk/media/8557/en-et-aarsplan-skal-saettetempo-paa-den-groenne-omstilling.pdf.

Sorrell, S., Gatersleben, B. and Druckman, A. (2020) 'The limits of energy sufficiency: A review of the evidence for rebound effects and negative spillovers from behavioural change', Energy Research \& Social Science, 64, 101439.

Tran, M. et al. (2013) 'Simulating early adoption of alternative fuel vehicles for sustainability', Technological Forecasting and Social Change, 80(5), pp. 865875. doi: 10.1016/j.techfore.2012.09.009.

Wells, P., and Xenias, D. (2015). 'From 'freedom of the open road'to 'cocooning': Understanding resistance to change in personal private automobility', Environmental Innovation and Societal Transitions, 16, pp. 106-119. 